\title{
Lidar Measurements of the Vertical Distribution of Aerosol Optical and Physical Properties over Central Asia
}

\author{
Boris B. Chen, ${ }^{1}$ Leonid G. Sverdlik, ${ }^{1}$ Sanjar A. Imashev, ${ }^{1}$ Paul A. Solomon, ${ }^{2}$ Jeffrey Lantz, ${ }^{3}$ \\ James J. Schauer, ${ }^{4}$ Martin M. Shafer, ${ }^{4}$ Maria S. Artamonova, ${ }^{5}$ and Gregory R. Carmichael ${ }^{6}$ \\ ${ }^{1}$ Kyrgyz-Russian Slavic University, 44 Kievskaya Street, 720000 Bishkek, Kyrgyzstan \\ ${ }^{2}$ Office of Research and Development, U.S. EPA, 944 E. Harmon Avenue, Las Vegas, NV 89119, USA \\ ${ }^{3}$ Office of Radiation and Indoor Air, U.S. EPA, 944 E. Harmon Avenue, Las Vegas, NV 89119, USA \\ ${ }^{4}$ University of Wisconsin, Wisconsin State Laboratory of Hygiene, 660 North Park Street, Madison, WI 53706, USA \\ ${ }^{5}$ Institute of Atmospheric Physics, Moscow 109017, Russia \\ ${ }^{6}$ Department of Chemical and Biochemical Engineering, University of Iowa, Iowa City, IA 52242, USA
}

Correspondence should be addressed to Boris B. Chen; lidar@istc.kg

Received 16 May 2013; Revised 14 August 2013; Accepted 14 August 2013

Academic Editor: Helena A. Flocas

Copyright (C) 2013 Boris B. Chen et al. This is an open access article distributed under the Creative Commons Attribution License, which permits unrestricted use, distribution, and reproduction in any medium, provided the original work is properly cited.

\begin{abstract}
The vertical structure of aerosol optical and physical properties was measured by Lidar in Eastern Kyrgyzstan, Central Asia, from June 2008 to May 2009. Lidar measurements were supplemented with surface-based measurements of $\mathrm{PM}_{2.5}$ and $\mathrm{PM}_{10} \mathrm{mass}$ and chemical composition in both size fractions. Dust transported into the region is common, being detected $33 \%$ of the time. The maximum frequency occurred in the spring of 2009. Dust transported to Central Asia comes from regional sources, for example, Taklimakan desert and Aral Sea basin, and from long-range transport, for example, deserts of Arabia, Northeast Africa, Iran, and Pakistan. Regional sources are characterized by pollution transport with maximum values of coarse particles within the planetary boundary layer, aerosol optical thickness, extinction coefficient, integral coefficient of aerosol backscatter, and minimum values of the Ångström exponent. Pollution associated with air masses transported over long distances has different characteristics during autumn, winter, and spring. During winter, dust emissions were low resulting in high values of the Ångström exponent (about 0.51 ) and the fine particle mass fraction (64\%). Dust storms were more frequent during spring with an increase in coarse dust particles in comparison to winter. The aerosol vertical profiles can be used to lower uncertainty in estimating radiative forcing.
\end{abstract}

\section{Introduction}

The solution to many practical problems in the field of environmental and human health protection is connected with the need for improved information about atmospheric aerosols, in particular, levels of pollution and the physicochemical properties of particles. This type of information is especially important for the Central Asian continent due to the large regions with high levels of particulate matter (PM) emissions and a lack of ambient measurement data [1]. In spite of the increasing capabilities to monitor aerosol transport from satellites, there are very limited data for surfacebased vertical measurements of aerosol optical properties to validate satellite results and to provide higher spatial resolution than what can be obtained by satellites.
Radiative effects of the atmospheric aerosol are mainly connected to their chemical properties [2]. Due to the lack of extensive data on aerosol vertical profiles, there are large uncertainties in forecasting atmospheric radiative forcing due to differences in the vertical profiles of the atmospheric aerosol as applied in models. The ability to retrieve information on the spatial structure of aerosols by ground-based remote multiwavelength laser sensing allows for not only the identification of particle layers aloft but also the ability to study transport processes and to lower uncertainty in estimates of radiative forcing that are sensitive to the vertical distribution of aerosols [3]. There is also value in studying the vertical structure of particles in locations close to major dust emissions sources [4]. Therefore, in recent years, Lidar measurements are widely used for studying the spatial and 


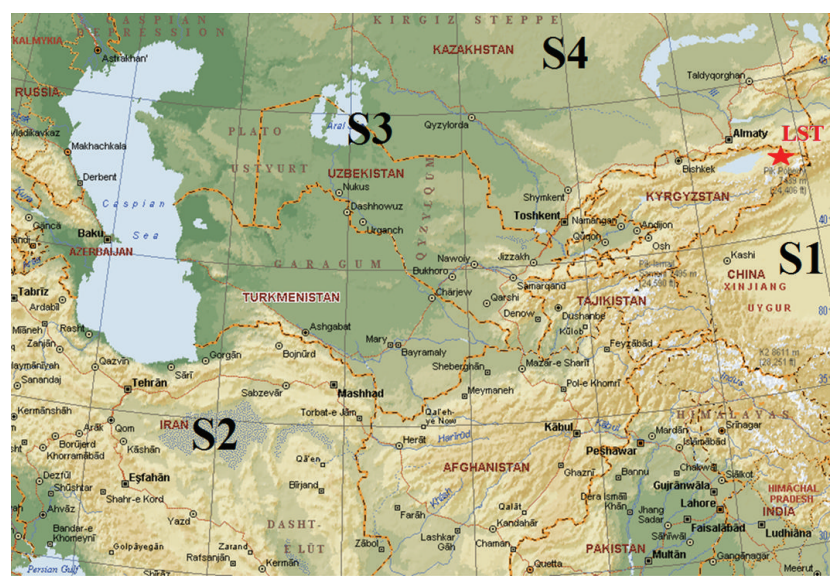

FIGURE 1: Source regions impacting study site. Approximate LST site location $(*)$.

temporal variability of aerosol properties, in particular, during Asian (Aerosol Characterization Experiment-Asia (ACEAsia)) and Near Eastern (Saharan mineral dust experiment (SAMUM)) dust events [5-7].

The Lidar Station Teplokluchenka (LST) KRSU $\left(42^{\circ} 27^{\prime} 49.38^{\prime \prime} \mathrm{N}, 78^{\circ} 31^{\prime} 44.17^{\prime \prime} \mathrm{E}, 1921 \mathrm{~m}\right.$ a.s.l.) is a unique site in Central Asia where atmospheric aerosol measurements are obtained using a multiwavelength laser system-Lidar. This location, in eastern Kyrgyzstan, is in close proximity to the largest sources of dust in Central Asia, for example, Aral Sea basin, Taklimakan desert, and SE China's Atmospheric Brown Cloud (ABC) (Figure 1). Measurements at LST can help better understand pollution transport to and within Central Asia and their influence on the ecology of the region.

In this paper, the vertical distribution of the optical and physical properties of aerosols, up to about $12 \mathrm{~km}$, is obtained from Lidar backscatter signals and used to study pollution transport to Central Asia from various source regions within and external to Central Asia. Lidar measurements were obtained from June 2008 to May 2009, in conjunction with a larger study (Transcontinental Transport of Air Pollution from Central Asia (International Science and Technology Center Project No. 3715)) designed to characterize PM mass and chemical composition and source impacts at two sites in Kyrgyzstan [1].

\section{Methods}

Optical and microphysical characteristics of the atmosphere aerosol were retrieved from the backscatter signal of a multiwavelength $\operatorname{Lidar}(\lambda=355,532$, and $1064 \mathrm{~nm})$ that included channels for polarisation $(\lambda=532 \mathrm{~nm})$ and vibrational Raman scattering (RS) by atmospheric nitrogen $(\lambda=387 \mathrm{~nm})$. The relative contribution of nonspherical particles to the backscatter signal was determined based on the polarisation measurements. Separation of particle and molecular contributions to the total backscattered signal was based on Raman technique [8]. This configuration allows sensing of aerosol in the boundary layer and free troposphere $\left(0.8 \mathrm{~km} \leq h_{i} \leq 12.0 \mathrm{~km}\right)$. The full geometric overlap of the laser beam and the telescope field of view is reached at $0.8 \mathrm{~km}$ a.g.l., defining the lower limit of the vertical height of the Lidar measurements. Measurements of RS were acquired at night, whereas total aerosol optical depth (AOD) at several wavelengths $(\lambda=340,380,500,675,870$, and $1020 \mathrm{~nm}$ ) was made just outside the Lidar complex using the Microtops II sun photometer. During simultaneous Lidar and radiometric measurements, the operating time of the Lidar was synchronised with the sun photometer measurements.

The analysis focused on special observations without a fixed schedule to capture events characterized by significant changes in the optical condition of the atmosphere (e.g., dust transport, $\mathrm{ABC}$ ). Lidar sensing also was conducted two times a week on Mondays and Thursdays as has occurred in the past. The Navy Aerosol Analysis and Prediction System (NAAPS) model was used to forecast measurement periods. To obtain sufficient statistical information, Lidar measurements were obtained for at least $0.5 \mathrm{hr}$. The elastically backscattered signal was recorded in the analogue mode and the RS signal was recorded in the photon counting mode. The laser pulse repetition frequency was $9-10 \mathrm{~Hz}$. The raw vertical range resolution of the Lidar signal was $15-30 \mathrm{~m}$. The lower vertical limit of the measurement range was $0.8 \mathrm{~km}$ as noted above, and the top measurement level was the height of the tropopause (10-12 km).

Data processing of single-wavelength, multiwavelength, and polarization sensing was obtained using retrieval algorithms of the aerosol optical characteristics based on simultaneously processing Lidar and photometric measurements with and without the RS signal [9]. Models using a step distribution of the Lidar ratio LR (particle extinction-tobackscatter ratio) were used when layers were observed during the day and night with their bottom border above $4 \mathrm{~km}$. Solution of Lidar equations along with retrieval of optical and microphysical parameters of aerosol on the bases of multiwavelength Lidar sensing including Raman signals from atmosphere nitrogen is performed by the iteration scheme using the Fernald transformation [10]. The error in the backscatter coefficient at $532 \mathrm{~nm}$ in the troposphere is about $40 \%$. This can be explained by the small value of the aerosol backscatter coefficients relative to the Rayleigh coefficients that results in large errors in aerosol backscatter from the Lidar signal even at small errors in signals and molecular atmosphere density. In the general case, the same is true for the extinction Raman coefficient (30\%), but for larger values of optical thickness, this error drops to $12 \%$. For an aerosol layer with optical thickness greater than a certain value ( 0.02 for assumed values of errors), the error in the integral aerosol parameters retrieval does not exceed $30 \%$ [11].

Measurements of AOD were selected under cloud-free conditions based on sun photometer observations during the same hour of the Lidar observations. Expected accuracy of the AOD measurements estimated by the photometer is \pm 0.02 (e.g., [12]). When aerosol layers were identified, in particular dust, the ground-based Lidar measurements were augmented with results from satellite Lidar (Cloud-Aerosol Lidar and Infrared Pathfinder Satellite Observations, CALIPSO), along with comparison to the NAAPS aerosol model and back 

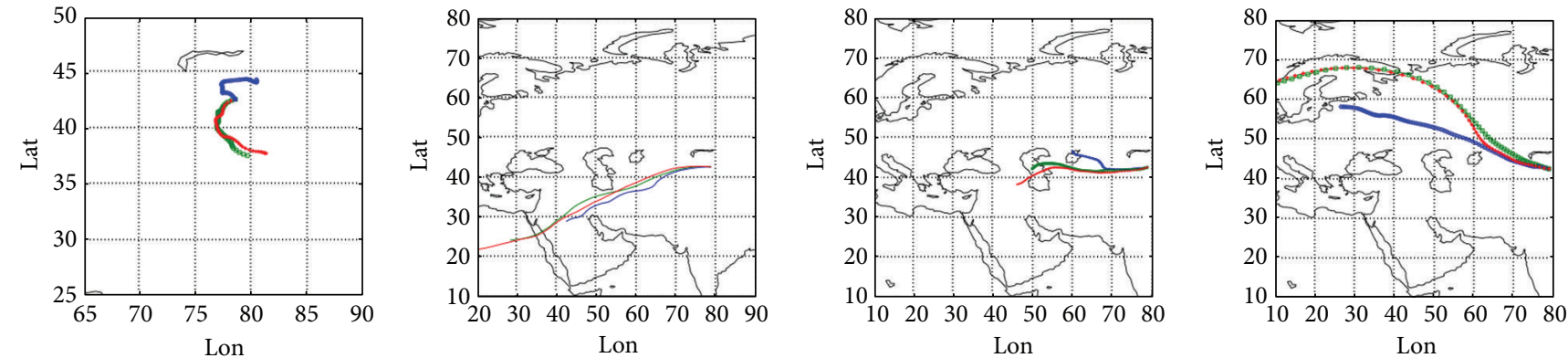

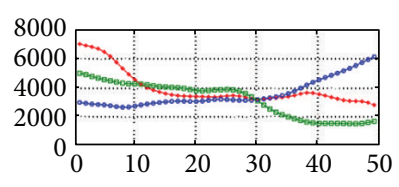

(a)

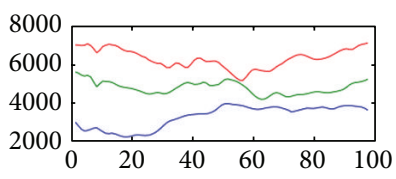

(b)

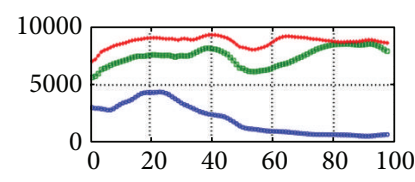

(c)

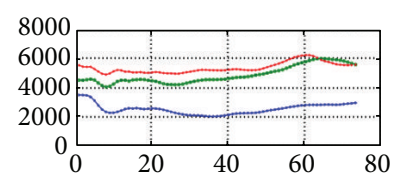

(d)

FiguRE 2: Examples of 96-hour air mass back trajectories at 3, 5, and 7 km a.g.l. From sources S1, 07.06 .2009 (a); S2, 15.03 .2009 (b); S3, 12.07.2009 (c); and S4, 29.04.2009 (d).

trajectory analysis using NOAA’s Hybrid Single-Particle Lagrangian Integrated Trajectory Model (HYSPLIT). Lidar measurements also were supplemented with surface-based measurements of $\mathrm{PM}_{2.5}$ and $\mathrm{PM}_{10}$ mass and chemical composition of PM in both size fractions obtained as part of a larger study [1].

\section{Results}

3.1. Main Sources of Pollutant Transport. To determine the sources of pollution that influence the LST, back trajectories were calculated at three arrival heights $(3 \mathrm{~km}, 5 \mathrm{~km}$, and $7 \mathrm{~km}$ a.g.l) using the NOAA HYSPLIT model [13]. These heights of aerosol transport were chosen based on topography and previous analyses of long-term Lidar profiles obtained at LST, which showed that a height of $3 \mathrm{~km}$ a.g.l. reflects the average top border of the PBL in this mountainous region, whereas 5 and $7 \mathrm{~km}$ were the top borders of the transport layer depending on the synoptic situations.

Based on back trajectory analysis, four main source areas of pollution transport were identified in Central Asia:

(i) source 1 (S1): South Asia, including Central Asia mountain massif and Taklimakan desert;

(ii) source 2 (S2): the Middle East, including deserts of Libya, Arabia, and plateau of Iran;

(iii) source 3 (S3): Aral Sea basin, including Western Kazakhstan, Kara-Kum, and Kyzyl-Kum deserts;

(iv) source 4 (S4): East Europe and European part of Russia, Western Siberia, and East Kazakhstan, including Betpak-Dala, Moyinkum, and Taukum deserts.

Figure 2 shows examples of 96 hours back trajectories at heights of 3, 5, and $7 \mathrm{~km}$ above the surface from sources S1-S4.

3.2. General Circulation Conditions during the Measurement Period. Synoptic processes in Central Asia were grouped into three types of trajectories based on modern classifications (114) [14] that are described as follows:

(i) latitudinal type $L$ processes: (1) South Caspian cyclone, (2) Murgab cyclone, (5) northwest invasion, (7) worrying activity, (9) southwest periphery anticyclone, (9a) southeast periphery anticyclone, (10) west invasion, and (14) west cyclone;

(ii) meridional south type $M_{S}$ processes: (3) top Amudaria cyclone, (4) broad removal of warm air, (11) summer thermal depression, (13) warm sector cyclone, and (13a) prefrontal position;

(iii) meridional northern type $M_{N}$ processes: (6) north invasion, (8) nonmobile high cyclone over Central Asia, (9a) southeast periphery anticyclone, (12) small gradient fields of increased pressure, and (12a) small gradient fields of decreased pressure.

The thermodynamic properties of air masses and weather conditions were divided into 5 groups.

Group 1. Southern cyclones (processes 1, 2, and 3) are characterized by arrival to the region of damp tropical air masses generated over the Mediterranean, the north of Arabian Peninsula, and Mesopotamia, occurring mainly during the cold period (autumn-winter seasons). Processes in this group are indicated by warm winter weather and precipitation in Central Asia. In the troposphere, southwest air streams prevail with sharp meridian circulation over the European territory of Russia (ETR) and Western Siberia when Central Asia is in a forward cyclonic part of the high macroscale hollow. In summertime, this group is practically absent. For processes 1 and 2, pollutant transport is mainly from S2 and for process 3 from S1.

Group 2. Cold fronts, western cyclones (processes 5, 6, 7, 8, $9 \mathrm{a}, 10$, and 14) are characterized by damp cold air masses that more often arrive from midlatitudes and are rare for Arctic or 
TABLE 1: Weather types with dominant synoptic scale motion ${ }^{1}$.

\begin{tabular}{|c|c|c|c|c|c|}
\hline $\begin{array}{l}\text { Basic weather } \\
\text { type }\end{array}$ & Extended type & Synoptic motion & $\begin{array}{c}\text { Types of synoptic } \\
\text { processes }\end{array}$ & Pollution source & Vertical uplift \\
\hline \multirow[t]{3}{*}{ Convective } & Anticyclonic CA & Subsidence & 9 & $\begin{array}{c}\text { S3 in warm half } \\
\text { year, } \\
\text { S4-in cold }\end{array}$ & Up to $3 \mathrm{~km}$ \\
\hline & Indifferent CI & $\begin{array}{l}\text { Small-scale } \\
\text { circulations }\end{array}$ & $12,12 \mathrm{a}$ & $\mathrm{S} 1$ & Up to $1-3 \mathrm{~km}$ \\
\hline & Cyclonic CC & Lifting & 8 & S4 & All troposphere \\
\hline \multirow{3}{*}{ Advective } & West AW & $\mathrm{W}$ at $500 \mathrm{hPa}$ & $5,7,10$, and 14 & $\begin{array}{c}\mathrm{S} 3-7,10, \text { and } 14 \\
\mathrm{~S} 4-5\end{array}$ & $\begin{array}{c}\text { Up to } 5-7 \mathrm{~km} \text { and } \\
\text { above }\end{array}$ \\
\hline & North AN & $\mathrm{NW}-\mathrm{N}$ at $500 \mathrm{hPa}$ & 6 & S4 & Up to $2-4 \mathrm{~km}$ \\
\hline & South AS & $\mathrm{S}-\mathrm{SW}$ at $500 \mathrm{hPa}$ & $4,11,13$, and $13 a$ & $\begin{array}{c}\mathrm{S} 1-4,11 \\
\text { S2-13 and } 13 \mathrm{a}\end{array}$ & Up to $2-5 \mathrm{~km}$ \\
\hline Mixed & M & $\begin{array}{l}\text { Active cyclone or } \\
\text { high frontal zone }\end{array}$ & $1,2,3,9 a$, and $9 b$ & $\begin{array}{c}S 1-3 \\
S 2-1,2 \\
S 3-9 a, 9 b\end{array}$ & $\begin{array}{c}\text { Up to } 5-7 \mathrm{~km} \text { and } \\
\text { above }\end{array}$ \\
\hline
\end{tabular}

${ }^{1}$ Definitions are in the text, Section 3.

tropical regions. In the troposphere, western, northwest, and northern air streams prevail. Process 9a southeast periphery of an anticyclone is included in this group, because, as a rule, it is the final phase of cold intrusion. Pollution transport occurs from S4 during processes 5, 6, and 8 and from S3 during processes 7, 9a, 10, and 14 .

Group 3. Anticyclones (processes 9 and 9a) are anticyclones with dry air masses that arrive more often from the midlatitudes and are cold and sometimes Arctic during the winter and warm and sometimes tropical during the warmer half of the year. In the troposphere, western and northwest transport prevails. For these situations, pollution transport occurs from source S3 during the warm half of the year and from source S4 during the colder part of the year.

Group 4. Low-gradient fields (processes 4, 11, 12, and 12a) are characterized by the arrival of weak, dry, and warm air masses, more often tropical in nature. In the summer, this air mass is often formed over Central Asia. The high barometric pressure is characteristic of summer conditions and is connected with weak flows of tropospheric transport mainly from the western and southwestern directions. Pollution sources in this case are S1 for processes 4 and 11 and S3 for processes 12 and $12 \mathrm{a}$.

Group 5. Contrast zone (processes 13 and 13a) is created before an intrusion of cold air when gradients of pressure, temperature, and other meteorological parameters are strong. This group is characterized by very warm and dry air and usually associated with a tropical air mass. Strong gradients of pressure and temperature promote the occurrence of warm prefrontal winds, fens, and, as a result, dust storms. Pollution transport is carried out from source S2.

Synoptic conditions over the region can be further grouped into three basic and seven expanded weather types (Table 1). The convective types describe weather situations where vertical motion predominantly influences the weather. The three convective weather types CA, CI, and CC differ by the sign of the synoptic scale vertical motion [15]. Anticyclone type CA is characterized by low wind speeds caused by subsidence and is predominant during both the warm and cold parts of the year, resulting in adiabatic warming and cloud dissipation. This synoptic motion does not induce upward vertical transport of air in the PBL. It is characteristic for synoptic condition 9 when pollution transport basically occurs from S3 and S4 during the warm (spring-summer seasons) and cold parts of the year, respectively.

Ascent of air caused by convergence at low altitude is predominant for the cyclonic type CC, resulting in adiabatic cooling and cloud formation with subsequent precipitation. It is characteristic for situation 8 with transboundary transport from S4. In this case, the polluted air is well mixed throughout the troposphere due to the relatively strong vertical uplift. The convective indifferent weather type, CI, is characterized by alternating small scale up- and downdrafts depending on terrain effects [16]. It is characterized by small gradient fields of low and high pressure that occur during synoptic conditions 12 and $12 \mathrm{a}$ when the vertical transport of the air mass does not exceed the height of PBL, and pollution transport occurs from regional source S1. The difference in the synoptic scale vertical motion of weather types CA and CC is considerably more pronounced than that between the three advective weather types described below.

The advective types include weather situations where the horizontal motion of the atmosphere predominates, so that in flat terrain, the vertical wind component is unimportant. However, orography can add vertical components at ascending mountain slopes that occur in the northern (AN) and southern (AS) directions of air mass movement (Table 1), increasing the transport speeds of the air mass. These weather types are characteristic during northern intrusions, synoptic condition 6, when transboundary transport is from S4; from the south, synoptic conditions 4 and 11, when transboundary transport is from S1; and from the southwest before the intrusion of a cold front, when warm dry air dominates, usually a tropical air mass (contrast zones 13 and 13a) and transport occurs from source S2. 
TABLE 2: Frequency distribution (in percent) of weather types during the study period.

\begin{tabular}{cccccc}
\hline & CA & CI & CC & A & M \\
\hline $2008-2009$ & 18.8 & 15.1 & 1.0 & 46.9 & 18.2 \\
\hline
\end{tabular}

The AW type comprises only one wind direction and is characterized by advection of maritime air masses from the Atlantic. The AN type occurs when the region is influenced by cold polar air masses after northern intrusions. The AS type comprises two wind directions and induces most of the pollutant transport from S2. The mixed type $\mathrm{M}$ describes weather situations where both the horizontal and the vertical wind components are significant and occurs when an active cyclone or a front is present. As a rule, polluted air masses are confined within the PBL. The frequency distribution of weather types observed during the study is shown in Table 2 . The frequency of occurrence of advective weather type A was the highest, followed by anticyclone type CA, then mixed type $\mathrm{M}$, and least by cyclonic weather type CC.

The frequency distribution of weather types and monthly average particle mass concentrations are presented in Figure 3. The frequency distribution of convective and advective weather types appeared to influence the mass concentration distribution of fine (particles less than $2.5 \mu \mathrm{m}$ aerodynamic diameter, AD) and coarse (particles between 2.5 and $10 \mu \mathrm{m} \mathrm{AD)}$ particles. Low PM concentrations were observed at the ground-based monitoring sites from October to January. While there was a minimum or total absence of cyclonic convection (type CC), there was considerable anticyclonic subsidence (type CA). At this time, the southwest periphery of anticyclone (type 9) becomes settled over the study area, and transport was from S4. From February to May, convection did not influence PM concentrations. During summer, high temperatures and associated thermal convection influenced all weather types, especially convective types CC and CI, and this is when maximum fine and coarse PM concentrations were observed at ground level. Cyclonic type, CC, was observed mostly in summer $(\sim 72 \%)$ with its highest frequency occurring in June ( 50\%). Thus, there was significant vertical air movement and transport of fine PM from S4 that occurred during these inactive high-altitude cyclones that resided over Central Asia (type 8). On the contrary, during the period from December to May, the lifting type (CC) was absent, and PM concentrations were low.

The mixed weather type $M$ prevailed in autumn and winter with pollutant transport from S1 and S3, as well as mainly S2, during the cold season. During the winter period, the frequency of advective types exceeded that of the convective, thereby suppressing vertical motion and creating conditions for transboundary transport of pollution from S4, with a simultaneous increase in transport of fine and coarse particles. Also, peak concentrations of both organic and inorganic carbon observed at the surface monitoring sites (1, Figure 3(c)) occurred during the winter months, with most of the organic carbon (OC) and elemental carbon (EC) observed in the fine fractions.

Advective weather types have an inverse annual cycle to the CI type, with a minimum occurrence during winter when vertical motion is suppressed by enhanced stability of the atmosphere [16] and maximal frequency during summer. All advective weather types were similar to the annual cycle type AS where the most frequent wind directions were S-SW at $500 \mathrm{hPa}$. Under these conditions, pollution was transported from $\mathrm{S} 1$ and $\mathrm{S} 2$.

Of the 241 measurement days obtained at the Lidar-Site, 79 days ( 33\%) included dust with the maximum frequency occurring during the spring of 2009 (39\% of the 79 days). Transport of fine particles in the form of sulphates was observed on 76 days (31.5\%) of which $41 \%$ occurred during autumn, $30 \%$ in winter, and $25 \%$ in summer. The vertical distribution of the optical and physical characteristics of the pollutant layers aloft and transported from the various source regions under the observed flow conditions is discussed in the next section.

\section{Discussion}

4.1. Regional Transport of Pollution (RTP). The variability of the PBL height and integral aerosol backscatter at $\lambda=$ $532 \mathrm{~nm}\left(\mathrm{IB}_{532}\right)$ in the range from $0.8 \mathrm{~km}$ to the top of the PBL is presented in Figure 4. PBL height was usually limited to $1.0-1.8 \mathrm{~km}$ in winter and $2.0-3.5 \mathrm{~km}$ in summer with average values of $1.5 \pm 0.5$ and $3.0 \pm 0.8 \mathrm{~km}$, respectively [17]. These results characterize the seasonal variability of the spatial and temporal distributions of aerosol and, in this case, the influence of dust transport from the Taklimakan desert. During the summer period, the average value of integral backscatter coefficient $(1.2 \pm 0.58) \times 10^{-3} \mathrm{sr}^{-1}$ exceeded that for winter $(0.38 \pm 0.28) \times 10^{-3} \mathrm{sr}^{-1}$. The range of $\mathrm{IB}_{532}$ under conditions of transport of Asian dust (e.g., Taklimakan) ranged from $0.9 \times 10^{-3} \mathrm{sr}^{-1}$ to $5.0 \times 10^{-3} \mathrm{sr}^{-1}$ (Figure 4). There were two relative maxima of $\mathrm{IB}_{532}$ : in spring (March-April) and summer (June). The lower number of dust intrusions during the cold period (November-February) was likely connected with lower dust emissions during this period [18]. Remote optical measurements and modeled data showed that dust transport was mainly associated with regional sources (Taklimakan desert and Aral Sea basin).

Regional transport (i.e., RTP) of pollution results in an increase in the concentrations of particles in the lower troposphere (including PBL). Transport typically occurred in a layer about $2.1 \pm 0.5 \mathrm{~km}$ thick with an average height of the top of the layer, equal to about $4.8 \pm 0.7 \mathrm{~km}$. Assuming a well-mixed boundary layer during RTP, the average fine particle mass coefficient (fine divided by fine plus coarse particle mass concentrations) measured at the surface was equal to $42.0 \pm 2.7 \%$, with an Ångström exponent of 0.06 , indicating the presence of coarse particles. In addition, the average extinction coefficient in the transport layer was high, $0.157 \pm 0,034$. The values of $\mathrm{AOD}_{500}($ at $\lambda=500 \mathrm{~nm})$, equal to 0.37 , differed slightly from $\mathrm{AOD}_{532}=0.31$ at $\lambda=$ $532 \mathrm{~nm}$. These results suggest that the aerosol was in the bottom layers (up to $5 \mathrm{~km}$ ), in which transport of coarse dust particles occurred. The average mass concentration of coarse particles (measured by difference between particles mass $<10 \mu \mathrm{m}$ minus fine particle mass concentration) was 


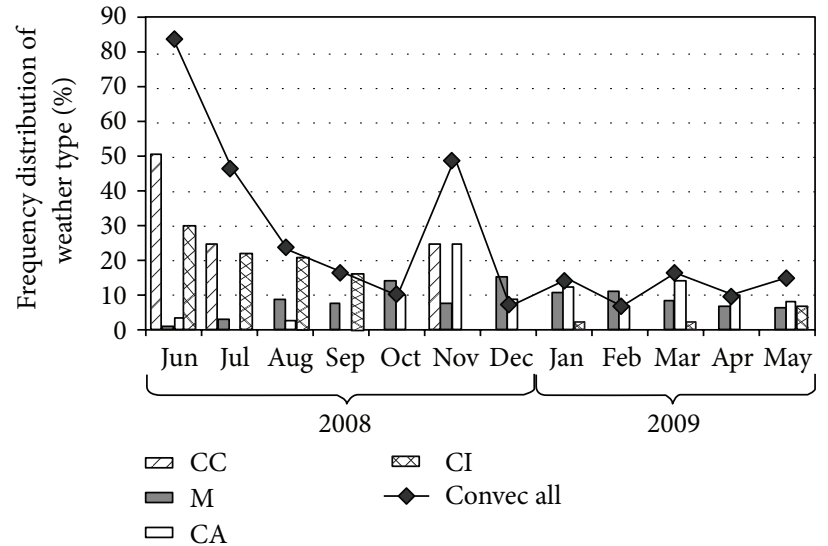

(a)

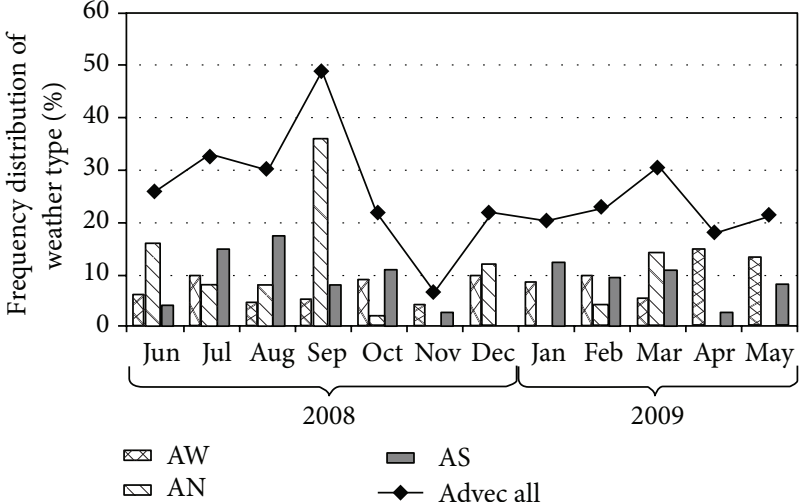

(b)

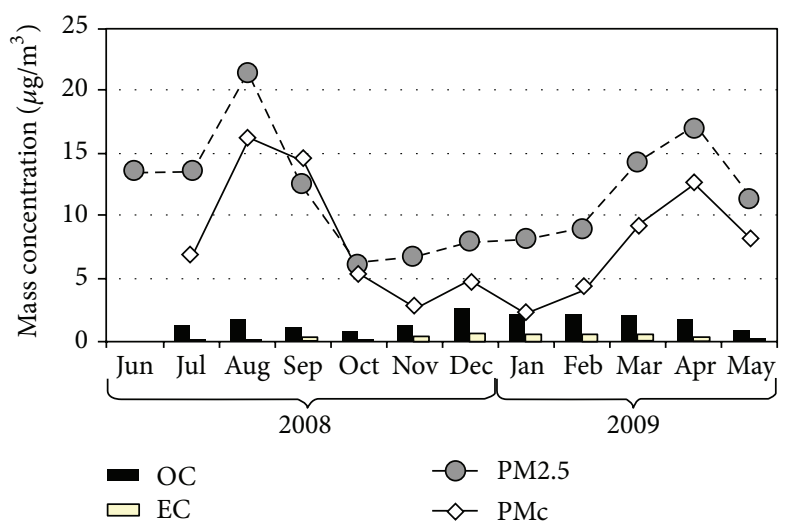

(c)

FIGURE 3: Frequency distribution of synoptic scale weather types ((a), (b)) and monthly average PM mass concentrations (c) observed during the study period, June 2008 through May 2009.

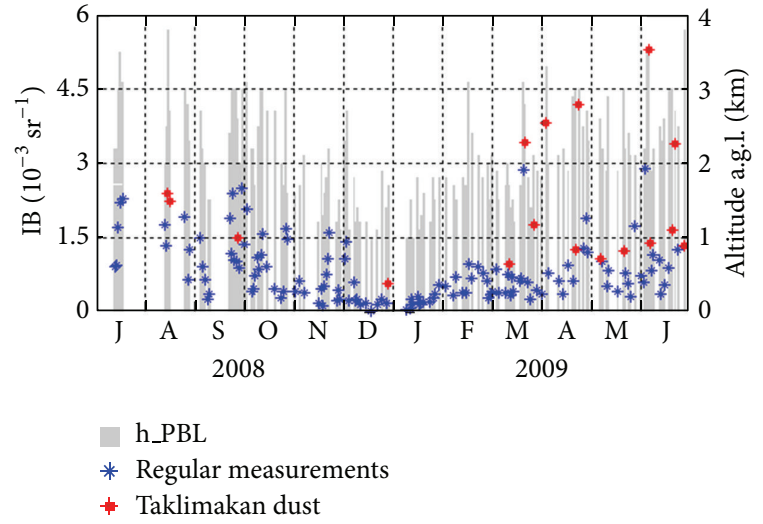

FIGURE 4: Boundary layer height and distribution of integral aerosol backscatter coefficient at $\lambda=532 \mathrm{~nm}\left(\mathrm{IB}_{532}\right)$ during July 2008 through June 2009. Dark blue markers: regular measurements, red: measurements in the conditions of dust transport from Taklimakan desert.

equal to $(20.7 \pm 4.7) \mu \mathrm{g} / \mathrm{m}^{3}$, reaching values of $41.0 \mu \mathrm{g} / \mathrm{m}^{3}$ at times (e.g., on 2 May 2009).

The $\mathrm{IB}_{532}$ in the transport layer during RTP was higher, in comparison to transport from other source areas, and was equal on average to $(0.0238 \pm 0.007) \times 10^{-3} \mathrm{sr}^{-1}$. Values of the Lidar ratio were typical for desert aerosol at humidity below $50 \%$ and on average equaled $17.57 \pm 3.15 \mathrm{sr}$. The depolarization ratio $\mathrm{DR}_{532}=0.09 \pm 0.01$ indicated that the coarse dust particles were mainly spherical due to condensation as a result of the high humidity in the transport layer. The single scattering albedo (SSA) in the pollutant transport layer was $0.971 \pm 0.005$. The particle size distribution was lognormal with two modes: (1) a coarse mode with a modal radius of $r_{c}=2.69 \pm 0.51 \mu \mathrm{m}$ and (2) a fine particle mode with a modal radius of $r_{f}=0.36 \pm 0.08 \mu \mathrm{m}$, with mode widths of $\sigma_{c}=2.38 \pm 0.40$ and $\sigma_{f}=1.41 \pm 0.009$, respectively. The real and imaginary parts of index of refraction were equal to $1.54 \pm 0.04$ and $0.021 \pm 0.008$, respectively, which characterizes transported aerosol as mineral particles with moderate absorption [19].

To further illustrate changes in aerosol properties with transport, a transport episode from S1 on 5-7 June 2009 was analyzed. During this period, small gradients of the low pressure (type 12a) were observed over the region, and the vertical extent of the transported aerosol remained within the PBL (Table 1). This process was preceded by type $9 \mathrm{~b}$-southern periphery of anticyclone, with transport from 


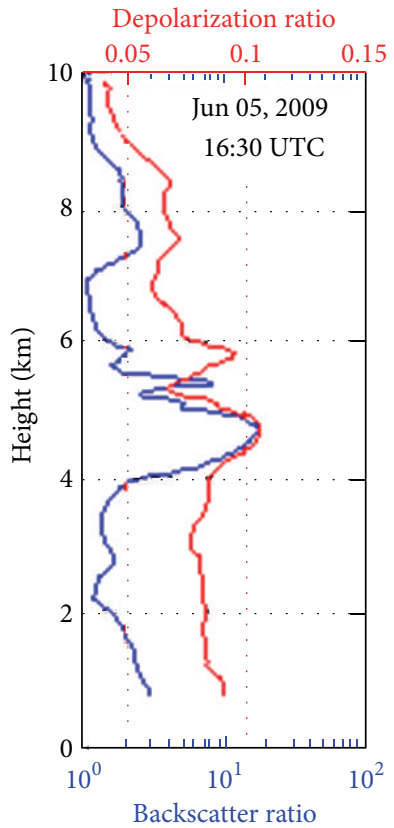

(a)

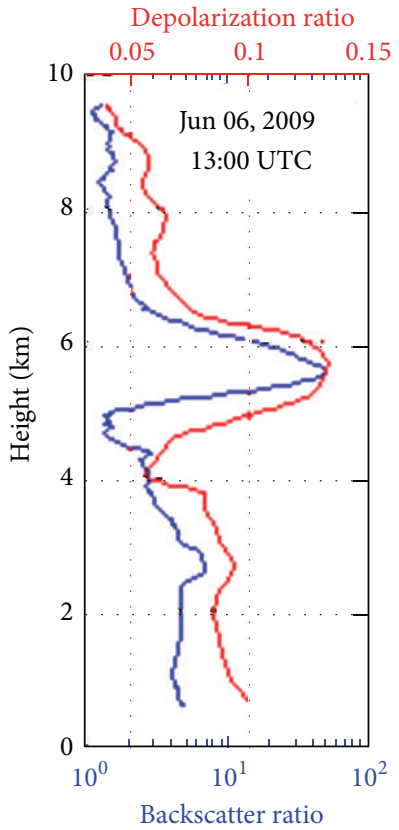

(b)

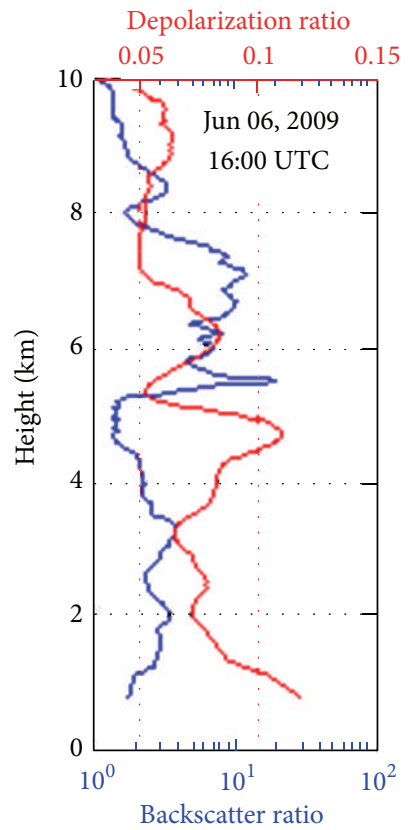

(c)

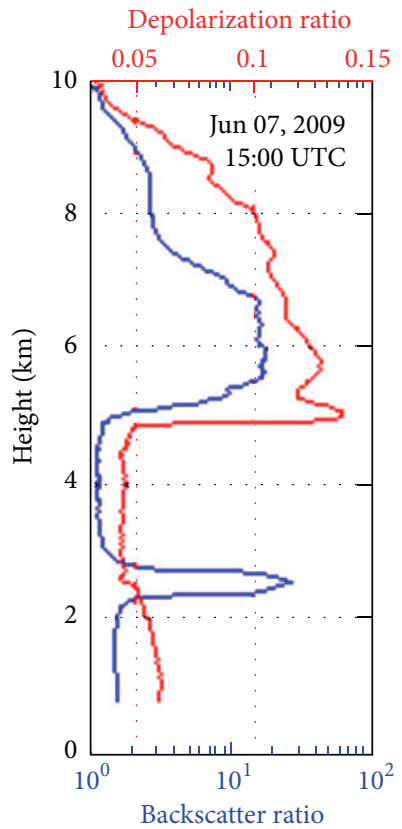

(d)

FIGURE 5: Vertical profiles of the backscatter and depolarization ratios on 05-07 June 2009.

Aral Sea basin (S3). In this case, the vertical extent of the aerosol was in the range of $5-7 \mathrm{~km}$ and above. The vertical profiles of the backscatter ratio $R$ (ratio of total to molecular backscatter) and the depolarization ratio $\mathrm{DR}_{532}$ are presented in Figure 5. This figure shows that, during synoptic condition $12 \mathrm{a}$, when the atmosphere was relatively stable, the aerosol layers remained mostly intact, having been transferred during the previous process, $9 \mathrm{~b}$, with most of the aerosol remaining in the free troposphere in the range from 4.0 to $8.0 \mathrm{~km}$. Increased values of $R$ were registered up to $10 \mathrm{~km}$, above which they decreased to background levels. During this period, values of $R$ within the PBL were 2-4 times higher than typical. Trajectories at several heights (from 0.5 to $5.0 \mathrm{~km}$ on $05-06$ June, and from 5.0 to $8.0 \mathrm{~km}$ on 07 June) showed that observed aerosol layers were due to pollutant transport from Northwest China (Figure 6). According to data from the NAAPS model, the dust originated from the Taklimakan desert, where it moved in a northwest direction reaching LST on 05 June (Figure 7).

Considerable variation in the vertical structure of the optical properties of the aerosol (Figure 5) is shown in the depolarization profiles (Figure 5) and the profiles of relative humidity (Figure $8(\mathrm{a})$ ). In the beginning of the episode (Figure 5(a)), moderate values of $\mathrm{DR}_{532}=(0.05-0.1)$ were observed, indicating particles with a general spherical shape due to the high relative humidity, and/or the particles were small in comparison to the $532 \mathrm{~nm}$ laser wavelength. On 06 June (Figure 5(b)), a simultaneous increase in $R$ (an increase of more than 50) and $\mathrm{DR}_{532}$ was observed in an aerosol layer at $5.0-7.0 \mathrm{~km}$ that may have resulted from multiple scattering due to the penetration of laser radiation into an optically dense cloud [20]. Mineral particles exposed to increased relative humidity $(\mathrm{RH}>80 \%)$ can act as condensation nuclei, causing clouds to form. The process of cloud formation on 06 and 07 June 2009, which usually accompanied the transport of the Asian dust, was registered by the CALIPSO Lidar (Figure 9). This satellite Lidar showed the presence of ice particles or cloud water in the dust layer.

Changes in the depolarization ratio were observed on 07 June in a layer at 5.0-8.0 km (Figure 5(d)), with even higher values of $\mathrm{DR}_{532}=0.15$ than that observed on previous days. Figure 8(a) shows that the relative humidity within the dust layer on 07 June was $50-60 \%$, which contrasted with the wetter air $(\mathrm{RH}>80 \%)$ at these heights, observed on $05-06$ June. Lower values of $\mathrm{RH}$ in the dust layer on 07 June were connected with intrusion of a relatively dry $(\mathrm{RH}$ in the source area was 35-60\%) air mass enriched by dust. Ice crystals were likely formed in this air mass, and their sedimentation to the bottom part of the layer may have resulted in higher values of $\mathrm{DR}_{532}$ [21]. Humidity strongly influences the optical properties of the aerosol layers, and the highest values of depolarization occurred at lower relative humidity. Similar variations in depolarization have been observed as a function of relative humidity for Asian dust layers at heights between 4.0 and $9.0 \mathrm{~km} \mathrm{[22].} \mathrm{DR}_{532}$ equal to $0.17-0.24$ also have been reported at lower RH (27-34\%) for Asian dust observed at a height of 2.5-4.0 km [23].

Comparison of AOD obtained by Lidar and the sun photometer allowed for calculation of the average Lidar ratio (LR) in a layer from the surface up to the calibration point. In this case, a linear distribution was used to estimate AOD in the shadow zone of the Lidar. For measurements on 


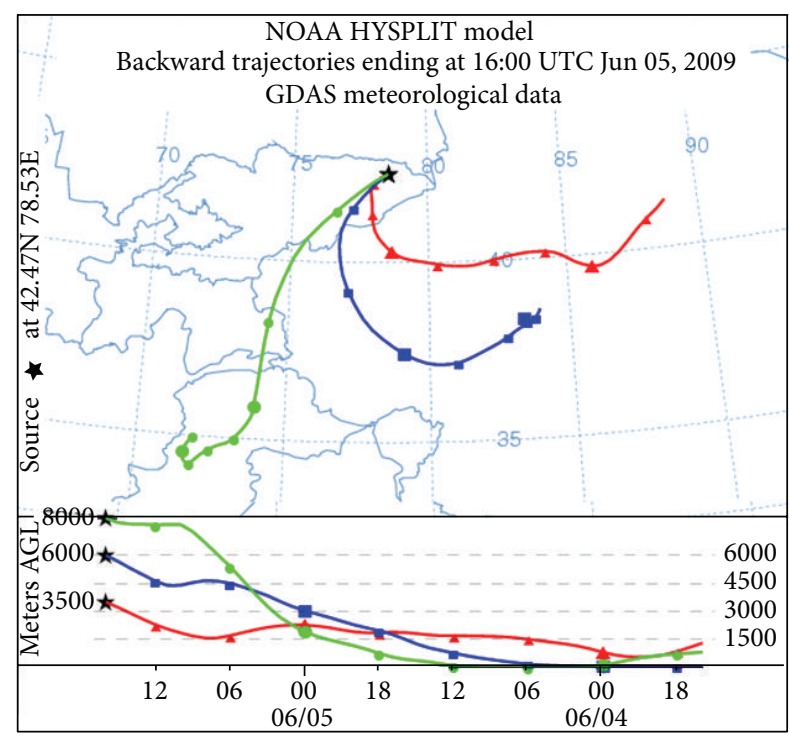

(a)

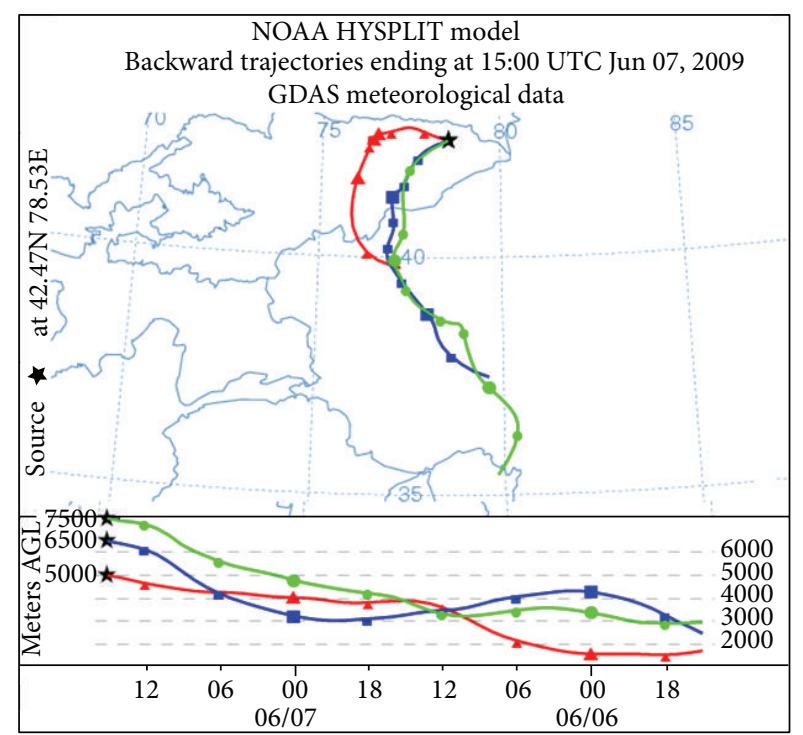

(b)

FIGURE 6: Back trajectories of air mass movement: (a) for arrival heights of 3500, 6000, and $8000 \mathrm{~m}$ (05 June 2009) and (b) 5000, 6500, and $7500 \mathrm{~m}$ (07 June 2009).

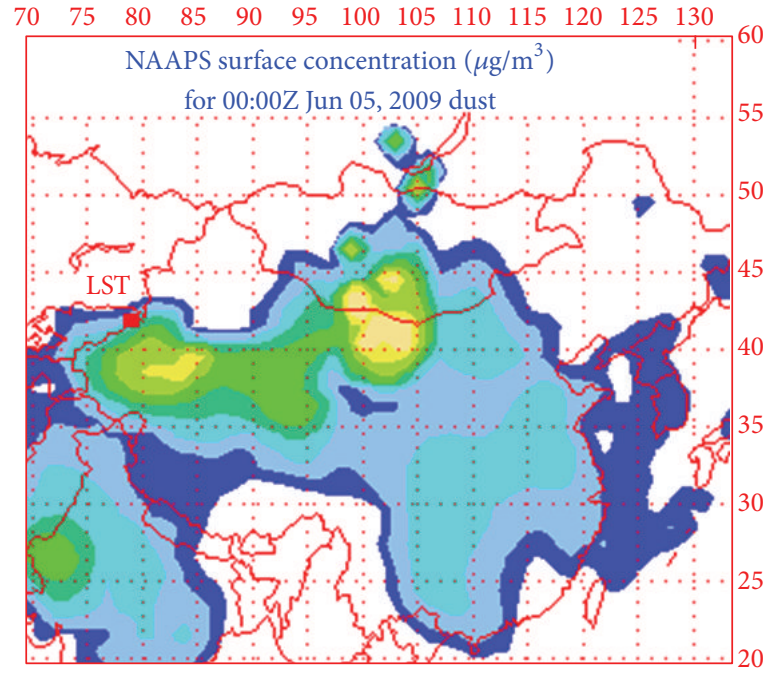

$20 \quad 40 \quad 80 \quad 160 \quad 320 \quad 640 \quad 1280 \quad 2560 \quad 5120$

(a)

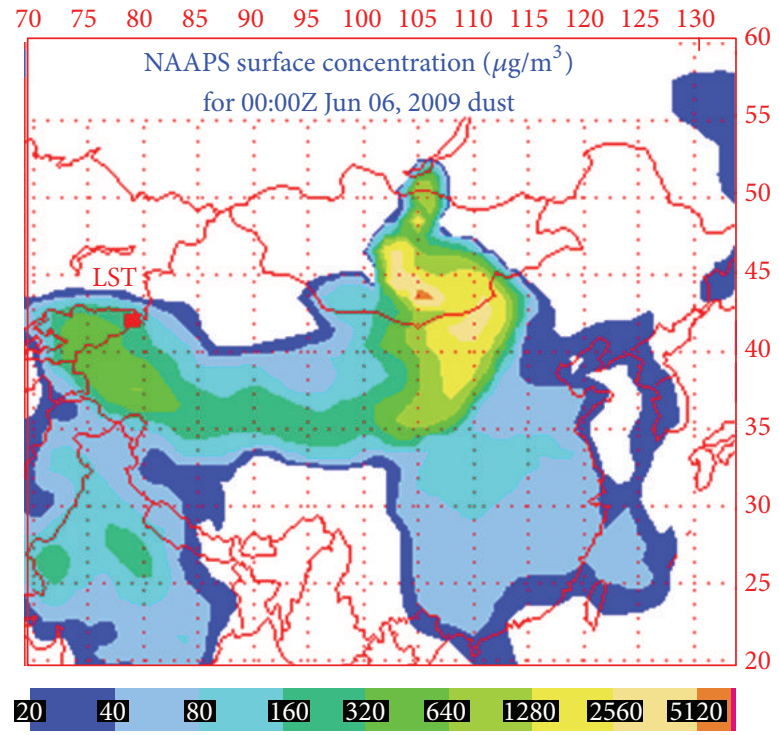

(b)

FIGURE 7: Surface mass concentration of dust aerosol on 05-06 June 2009 (NAAPS).

05 and 06 June, the average values of LR were 22 and $27 \mathrm{sr}$, respectively. In addition, the effective Lidar ratio, which leads to zero values of the backscatter coefficient above and below the layer, was estimated to examine the relationship between backscatter and aerosol extinction coefficients above $4.0 \mathrm{~km}$. Comparison of estimations of LR values determined by this method and application of the Raman technique was consistent with those of $[8,24]$. The SAMUM observations reveal that the Lidar ratio of dust (close to the Saharan source region) is around $55 \mathrm{sr}$ at the three laser wavelengths of 355 , 532, and $1064 \mathrm{~nm}$. A similar behavior of the Lidar ratio in aged-dust layers is also found in Eastern Asia (Lidar ratios
$<45 \mathrm{sr}$ ) [7]. A clear correlation was not observed between average values of Lidar ratio equal to 24,15 , and 20 sr on 05 , 06, and 07 June, respectively, and changes in RH. During 0507 June, the $\mathrm{LR}_{532}$ within the dust layers varied from 8 to $29 \mathrm{sr}$, with an average value of $18.3 \pm 7.4 \mathrm{sr}$. The presence of dust particles leads to higher values of LR in comparison to liquiddrop clouds ( $L R=6-20$ sr with average value of 11 sr) [25].

Profiles of aerosol backscatter coefficient $\left(\beta_{a}\right)$ at $\lambda=532$ and $1064 \mathrm{~nm}$, the color index $\left(\mathrm{A}_{532 / 1064}\right)$, and the depolarization ratio $\left(\mathrm{DR}_{532}\right)$ are shown in Figure 10. In aerosol layers between 5.0 and $8.0 \mathrm{~km}$, values of $\mathrm{A}_{532 / 1064}$ related to the backscatter at 532 and $1064 \mathrm{~nm}$ wavelengths ranged from 


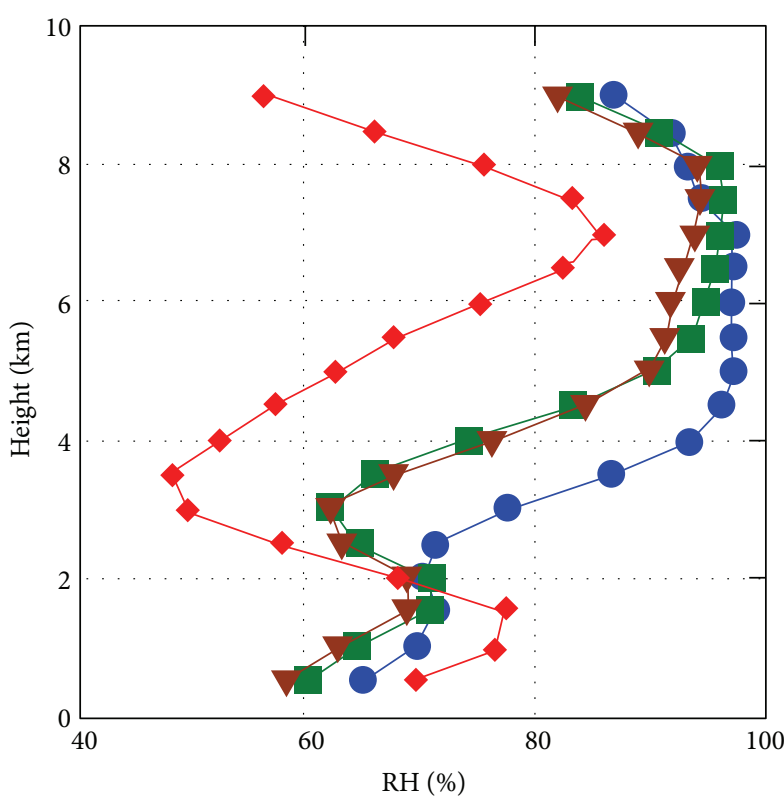

Jun 05, 2009, 16:00 UTC Jun 06, 2009, 13:00 UTC

(a)

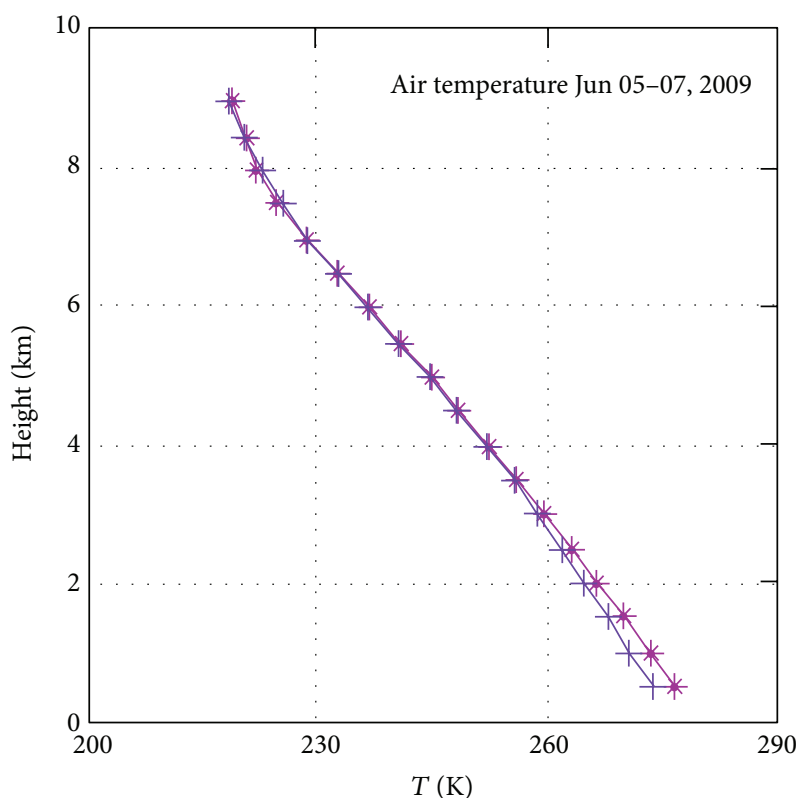

(b)

FIGURE 8: Vertical distribution of relative humidity (a) and air temperature (b) in the troposphere on 05-07 June 2009.

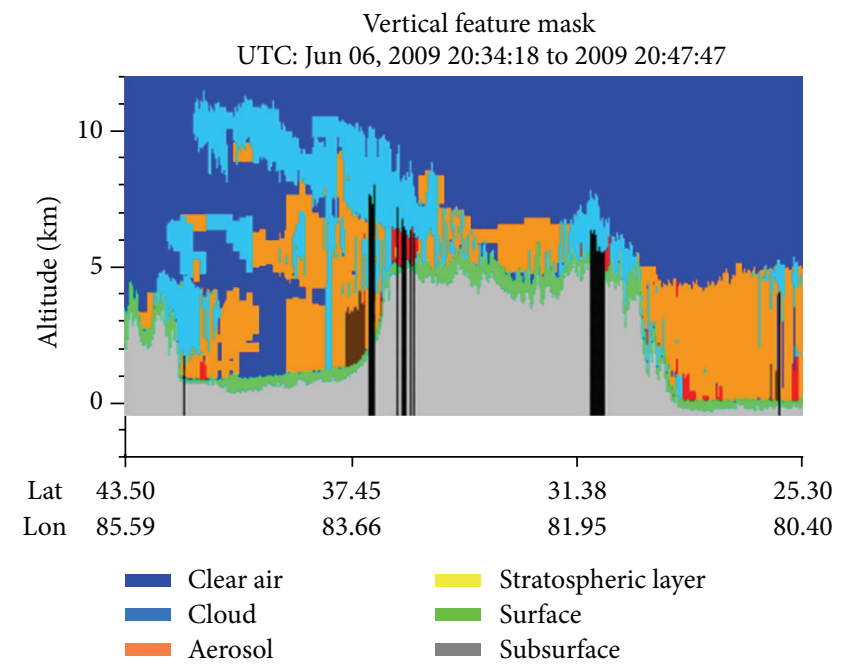

(a)

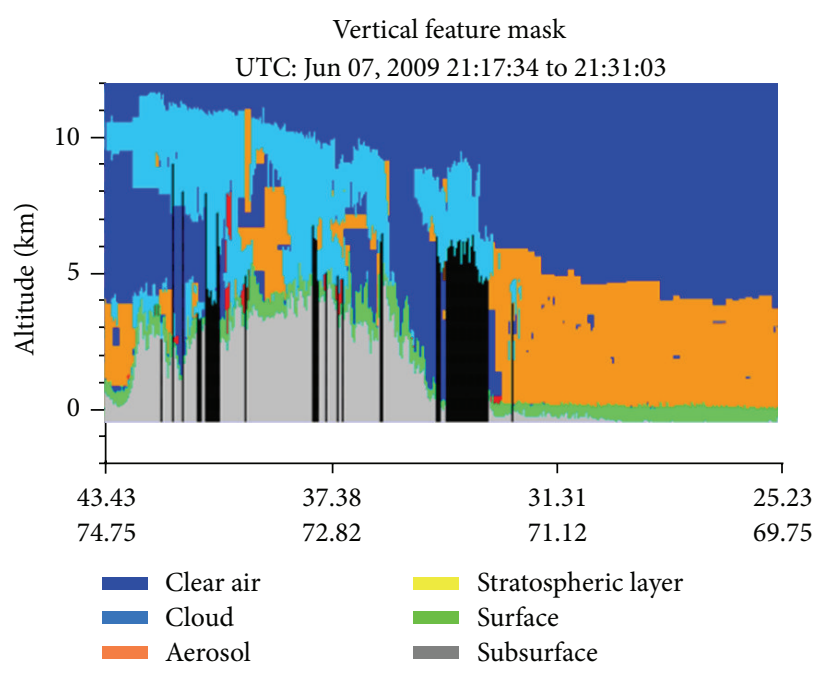

(b)

FIGURE 9: Vertical structure of atmospheric aerosol and clouds from CALIPSO data on 06 and 07 June 2009.

0.4 to 1.1 , indicating the presence of both fine and coarse particles with the prevailing contribution of the latter. Values of $\mathrm{A}_{532 / 1064}$ in this aerosol layer were close to those observed below $2.5 \mathrm{~km}$. Particle size distributions for layers with a vertical step of $\Delta h=0.5 \mathrm{~km}$ retrieved from the Lidar on $06-07$ June 2009 are shown in Figure 11. A strong influence of large particles, typical for the Asian dust, was observed. Values of effective radius varied in range of $0.55-1.25 \mu \mathrm{m}$ with a complex index of refraction equal to $1.50-1.60$ for the real part and $0.02-0.06$ for the imaginary part. For comparison, results from a sun photometry study of volumetric particle size distribution [26] also showed that coarse particles dominated in layers associated with Asian dust with a modal radius varying from $\sim 2.1$ to $2.9 \mu \mathrm{m}$.

Results of photometric measurements of $\mathrm{AOD}$ at $\lambda=$ $500 \mathrm{~nm}$, the Ångström exponents $\mathrm{A}_{380 / 675}$ and $\mathrm{A}_{675 / 870}$, and gravimetric measurements of fine particle mass concentration are shown in Figure 12. Retrieved values of 


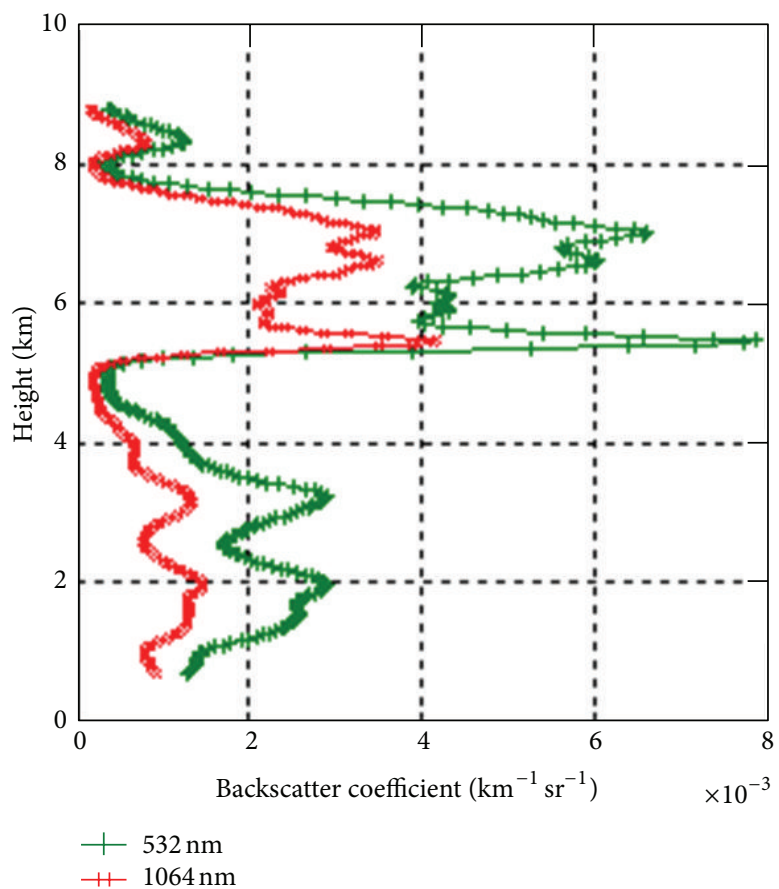

(a)

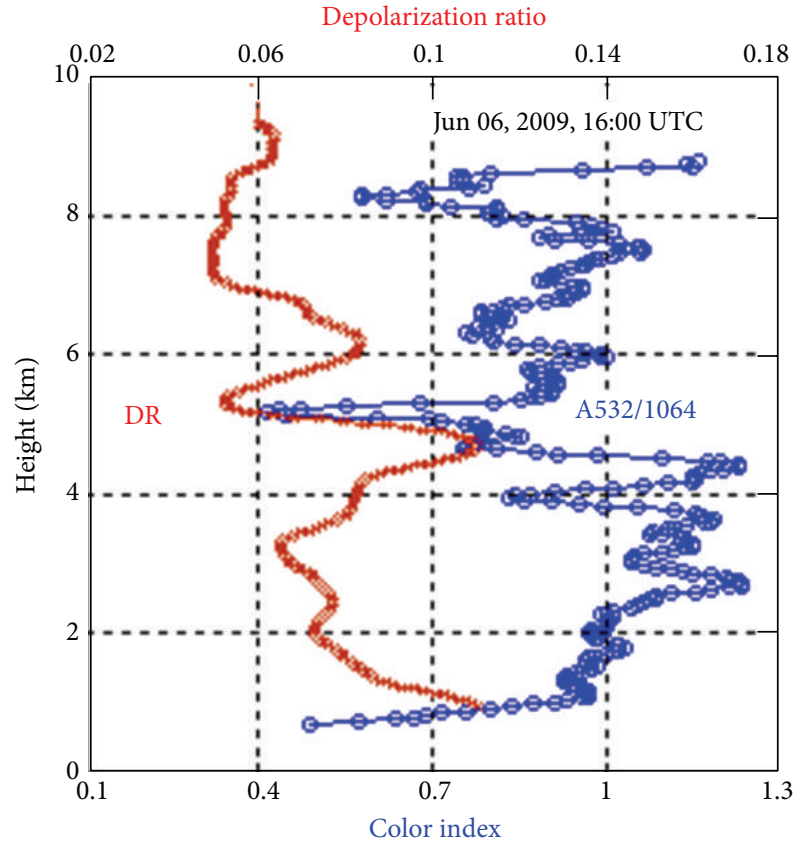

(b)

Figure 10: Profiles of backscatter coefficient at $\lambda=532$ and $1064 \mathrm{~nm}$ (a) and depolarization ratio and color index for $\lambda=532 / 1064 \mathrm{~nm}$ (b) on 06 June 2009.

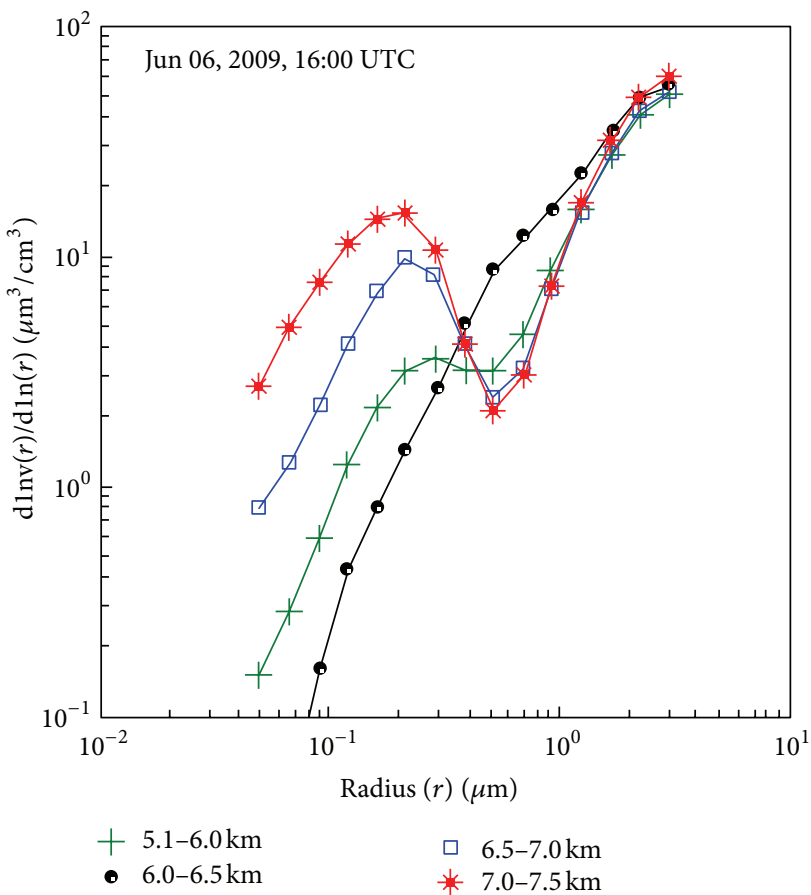

(a)

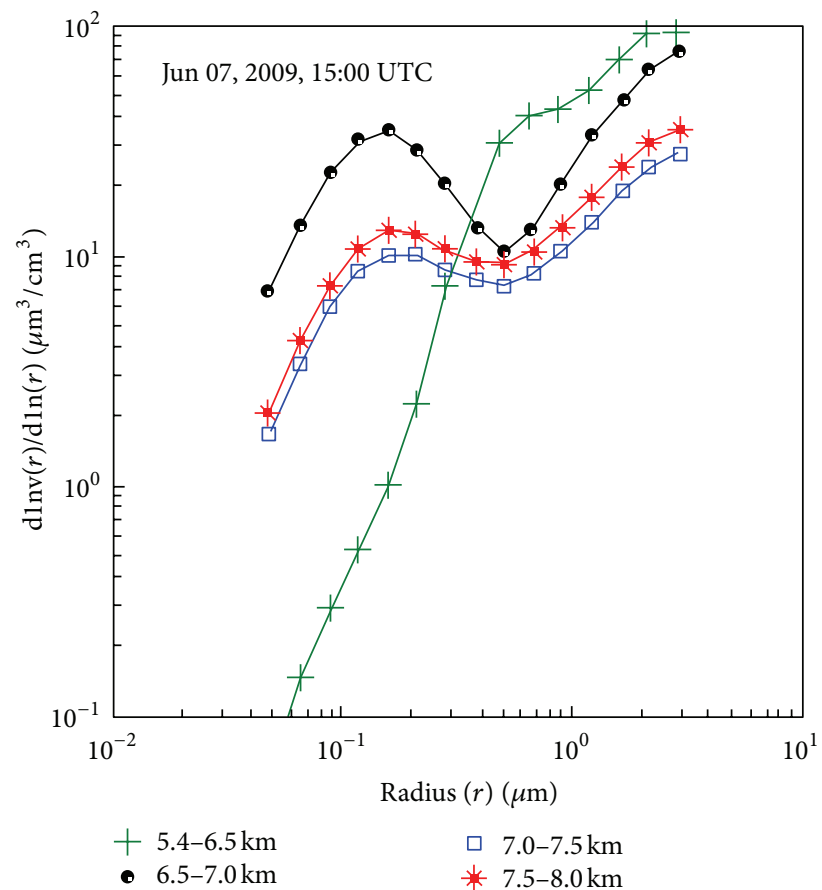

(b)

FIGURE 11: Volumetric particle size distribution, restored from Lidar measurements: 06 June 2009, 16:00 UTC (a) and 07 June 2009, 15:00 UTC (b). 


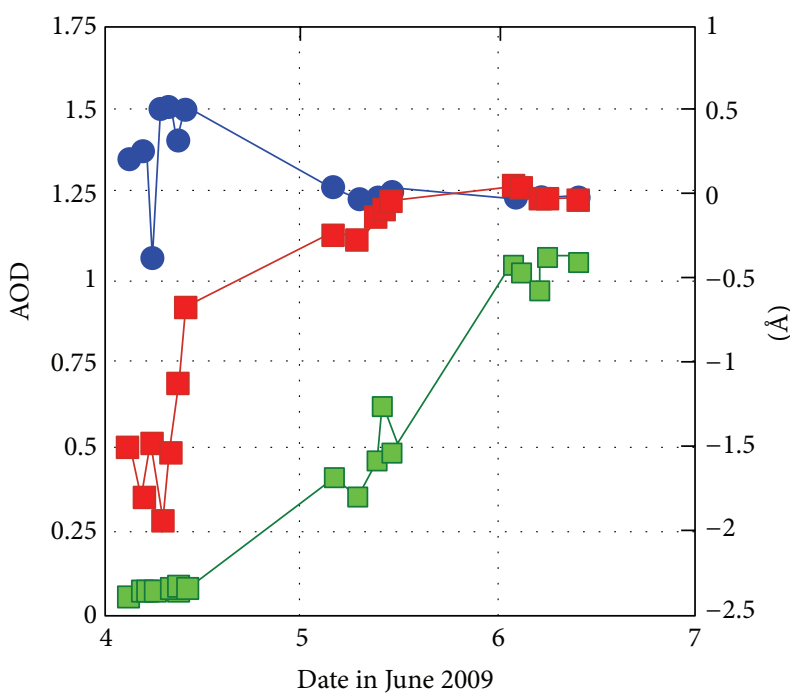

$-A_{380 / 675}$
$-A_{675 / 870}$
- AOD $_{500}$

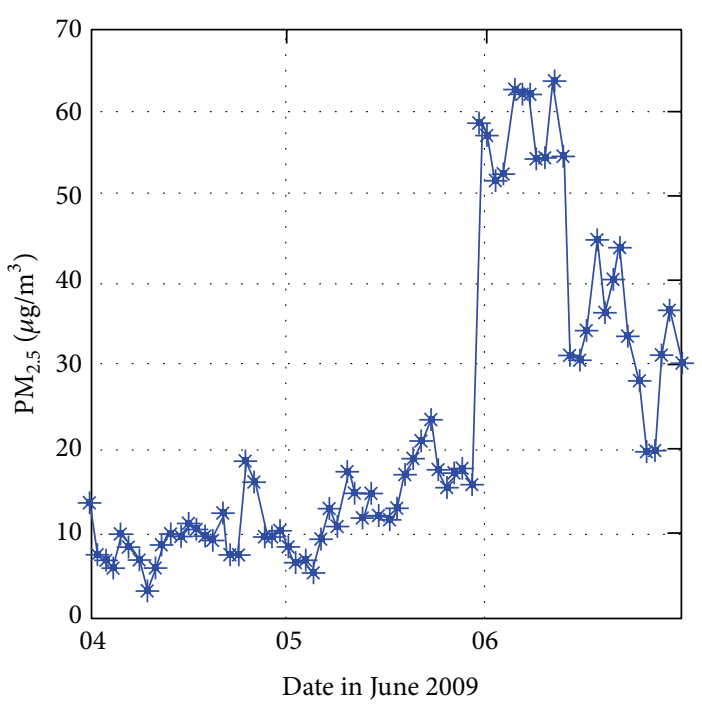

(b)

FIGURE 12: Change of AOD at $500 \mathrm{~nm}$ wavelength and the Ångström exponents (a) and $\mathrm{PM}_{2.5}$ mass concentration (b) on $04-06$ June 2009.

$\mathrm{AOD}=0.3-1.1$, the Ångström exponent from 0.5 to 0.1 , and fine particle mass concentrations greater than $30 \mu \mathrm{g} / \mathrm{m}^{3}$ are typical for Asian dust.

Anthropogenic aerosol also influences the Lidar-Site. For example, Lidar measurements indicated pollutant transport from the Fergana valley in the form of anthropogenic aerosol. This transport can be considered as separate regional transport. Often, this transport occurs at LTP from source S2. In these cases, the fine particle fraction is increased. Transport in general occurs in small layers above the layer of active turbulent mixing with a thickness of $1.1 \pm 0.2 \mathrm{~km}$. This transport occurs at the end of spring and the beginning of summer. The average fine particle mass fraction was equal to $56.9 \pm 0.9 \%$, and Angstrom parameter (1.3), respectively, indicating the higher fraction of fine particles in the aerosol layer during this time period. Furthermore, the extinction coefficient was low and equal to $0.025 \pm 0.003$. The average value of $\mathrm{AOD}_{500}=0.26$ indicated that along with the transport of anthropogenic aerosol there also was transport of dust particles. $\mathrm{AOD}_{532}$ calculated from the Lidar data in the transport layer was equal to $0.03 \pm 0.01$, indicating that the dust particles were above and below this layer, and the layer itself brought only a small contribution to aerosol loading. The Lidar ratio LR $=34.50 \pm 3.50 \mathrm{sr}$ is typical for pure continental aerosol at humidity of less than $50 \%$. The depolarization ratio $\mathrm{DR}_{532}=0.07 \pm 0.01$ indicated that the transported particles were mainly spherical.

Single scattering albedo in the pollutant transport layer was equal to $0.994 \pm 0.007$, and the particle size distribution was lognormal with two modes: a dust fraction with a modal radius of $r_{c}=1.10 \pm 0.60 \mu \mathrm{m}$ and a mode width of $\sigma_{c}=$ $1.70 \pm 0.30$ and a fine particle fraction with a modal radius of $r_{f}=0.12 \pm 0.00$ with mode width of $\sigma_{f}=1.65 \pm 0.45$. The real and imaginary parts of index of refraction were equal to $1.54 \pm 0.07$ and $0.003 \pm 0.002$, respectively, which correspond to mineral particles with poor absorption.

These results indicate that the aerosol properties differ depending on transport pathway and source region. AOD values of 0.26 in the transport layer from Fergana valley suggested transport of anthropogenic pollution and dust, whereas aerosol from S1 and S3 consisted mainly of larger dust particles. Extinction coefficients and values of imaginary part of index of refraction indicated that transport from regional sources S1 and S3 contained mineral particles with moderate absorption, whereas from Fergana valley the particles had weak absorption. In addition, SSA in the aerosol layer from Fergana valley $(0.994 \pm 0.007)$ was higher than that from other regional sources $(0.971 \pm 0.005)$.

4.2. Long-Range and Transboundary Transport of Pollution. Results of $\mathrm{IB}_{532}$ measurements in the free troposphere by Lidar from July 2008 to June 2009 are shown in Figure 13. $\mathrm{IB}_{532}$ was determined by heights between the top of the PBL to $10.0 \mathrm{~km}$. Most of the Lidar measurements represent atmospheric conditions with transport of air masses containing low aerosol loading. Measurements within this category can be characterized as cases with a minimum contribution from the free troposphere. The number of such cases characterized with values of $\mathrm{IB}_{532}<5.0 \times 10^{-3} \mathrm{sr}^{-1}$ made up approximately $65 \%$ of all measurements. In the rest of the cases (35\%), the integral backscatter coefficient of aerosol layers in the free troposphere varied from $5.0 \times 10^{-3} \mathrm{sr}^{-1}$ to $4.5 \times 10^{-2} \mathrm{sr}^{-1}$ with an average value of $\sim 2.3 \times 10^{-3} \mathrm{sr}^{-1}$. 


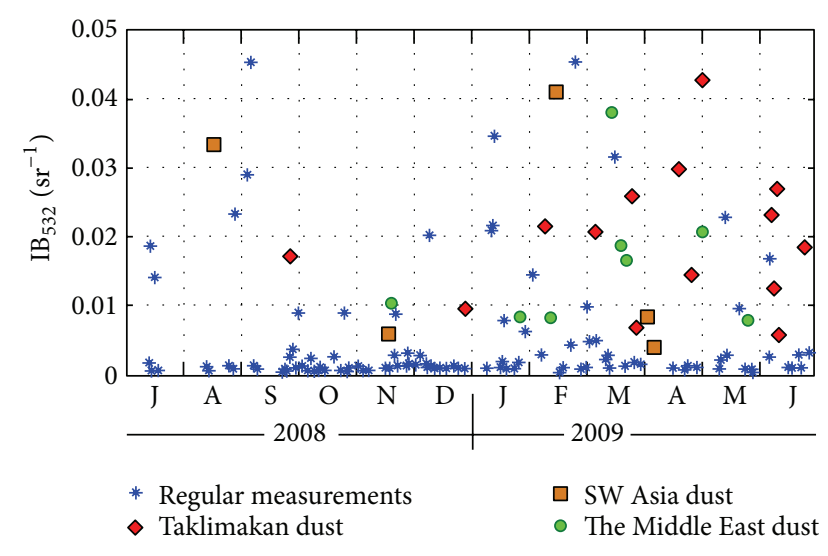

FIGURE 13: Distribution of integral aerosol backscatter coefficient at $\lambda=532 \mathrm{~nm}$, during the period July 2008 through June 2009. Dark blue markers: regular measurements $\mathrm{IB}_{532}$, red: dust transport from Taklimakan desert, brown: from southwest Asia, and green: from Arabia.

The overwhelming majority of cases with high aerosol loadings were in the period from February to June 2009. The large variability in $\mathrm{IB}_{532}$ in the free troposphere reflects the natural variability of the atmosphere and the influence of aerosol transport from several sources.

Air masses transported long distances have different characteristics during the cold (autumn-winter) and warm (spring) periods. The average ratio of the fine particle mass fraction, measured at the surface at the LST site for all periods, was equal to $55.4 \%$, which indicates the near equal importance of fine and coarse particles. The top border of the transport layer was above $7.0 \mathrm{~km}$ and the bottom border was above the top of the PBL. During the cold period, the average height of the top border of the transport layer $(7.1 \pm$ $0.4 \mathrm{~km})$ a.g.l. was lower than that during the warm period $(8.2 \pm 0.5 \mathrm{~km})$ a.g.l. The thickness of the transport layer in the latter case $(3.6 \pm 0.5 \mathrm{~km})$ was larger than that during the cold period $(2.1 \pm 0.4 \mathrm{~km})$.

During the cold period, only a few dust storms were observed and dust emissions were low. During these transport events, air masses were transported from the north and northwest (Kazakhstan, the Eastern Europe, and the European part of Russia) and primarily contained anthropogenic fine particles. Air masses observed at the Lidar-Site during the cold period had larger contributions from fine aerosol in comparison with the warm period. The aerosol in these air masses had the following optical characteristics: $\mathrm{IB}_{532}$ equal to $(0.0099 \pm 0.0039) \times 10^{-3} \mathrm{sr}^{-1}$; a high fine particle mass fraction equal to $64.2 \pm 2.7 \%$, an Ångström exponent equal to $0.51 \pm 0.10$; and a moderate extinction coefficient equal to $0.073 \pm 0.021$. PM10 mass concentrations at the surface site were on the average equal to $8.7 \pm 1.5 \mu \mathrm{g} / \mathrm{m}^{3}$. The Lidar ratio $(\mathrm{LR}=16.29 \pm 1.60 \mathrm{sr})$ was typical for desert aerosol at humidity below $50 \%$, and the depolarization ratio $\left(\mathrm{DR}_{532}=\right.$ $0.10 \pm 0.01)$ showed that the transported particles were mainly spherical but mixed partially with nonspherical particles. The SSA in the transport layer was equal to $0.995 \pm 0.003$ with a lognormal particle size distribution that contained two modes. The coarse mode had modal radius of $r_{c}=3.00 \pm$ $0.52 \mu \mathrm{m}$ with a mode width of $\sigma_{c}=1.78 \pm 0.17$, whereas the fine mode had a modal radius of $r_{f}=0.19 \pm 0.05 \mu \mathrm{m}$ with a mode width of $\sigma_{f}=2.06 \pm 0.30$. The real and imaginary parts of index of refraction were equal, respectively, to $1.46 \pm 0.03$ and $0.012 \pm 0.008$; that is, the transported anthropogenic fine aerosol contained an organic component with moderate absorption.

During the warm period, there was an increase in dust storms and therefore dust transport. $\mathrm{IB}_{532}$ increased to $0.0156 \pm 0.0063 \times 10^{-3} \mathrm{sr}^{-1}$, indicating higher scattering in the transport layer than during the cold period. The fine particle mass fraction decreased to $45.2 \pm 1.5 \%$, and the Ångström exponent decreased to $0.25 \pm 0.17$, indicating a larger contribution from coarse dust particles, in comparison with the cold season. Moderate levels of extinction coefficient, equal to $0.048 \pm 0.024$, were observed in the transport layers. The mass concentration of $\mathrm{PM}_{10}$ measured at the surface increased to $20.9 \pm 5.0 \mu \mathrm{g} / \mathrm{m}^{3}$ in comparison with the cold season $\left(8.7 \pm 1.5 \mu \mathrm{g} / \mathrm{m}^{3}\right)$. The Lidar ratio decreased from 16.29 to 13.67 , which is typical for dust aerosol at humidity below $50 \%$, but the depolarization ratio did not change in comparison with the cold period $\left(\mathrm{DR}_{532} \sim 0.10\right)$; that is, the transported particles were mainly spherical but mixed partially with nonspherical particles. The SSA in the pollution transport layer decreased down to $0.971 \pm 0.016$, which is typical for dust transported from Taklimakan. The particle size distribution was lognormal with two modes: the coarse or dust fraction had a modal radius of $r_{c}=3.07 \pm 0.35 \mu \mathrm{m}$ and a mode width of $\sigma_{c}=2.20 \pm 0.37$, whereas the fine mode had a modal radius of $r_{f}=0.22 \pm 0.06 \mu \mathrm{m}$ with a mode width of $\sigma_{f}=2.13 \pm 0.58$. The real and imaginary parts of the index of refraction were equal, respectively, to $1.52 \pm 0.04$ and $0.015 \pm 0.009$; that is, the aerosol included mineral particles with moderate absorption.

A typical case of long-range pollution transport was observed on 23 March 2009. On this day, there was a South Caspian cyclone (type 1) that passed through Central Asia from the southwest to the northeast. This process was preceded on 22nd of March by type 13-a warm sector cyclone, which transported pollution from S2. The vertical extent of the aerosol was $5-7 \mathrm{~km}$ and higher.

Figure 14 presents profiles of aerosol backscatter and depolarization ratio $(\lambda=532 \mathrm{~nm}$ at 15:00, 16:00, and 15:00 UTC) on March 23, 2009. Layers with high values of aerosol backscatter were found between 4.0 and $10.0 \mathrm{~km}$. The high relative humidity $(\mathrm{RH}>90 \%)$ in the layers located at heights up to $7.0 \mathrm{~km}$ resulted in low values of the depolarization ratio, indicating that the particles were mostly spherical although external mixing of nonspherical fine anthropogenic particles also was likely [27]. Large nonspherical particles were observed at the top of the layer $(7.5-10.0 \mathrm{~km})$ in good agreement with information about the variations in relative humidity in this high-altitude region (Figure 15).

Figure 16 shows back trajectories for the range from 5.5 to $7.5 \mathrm{~km}$, corresponding to layers at heights with high backscatter values. The intensive dust storms, which occurred in the Middle Eastern deserts, were likely the source of these 


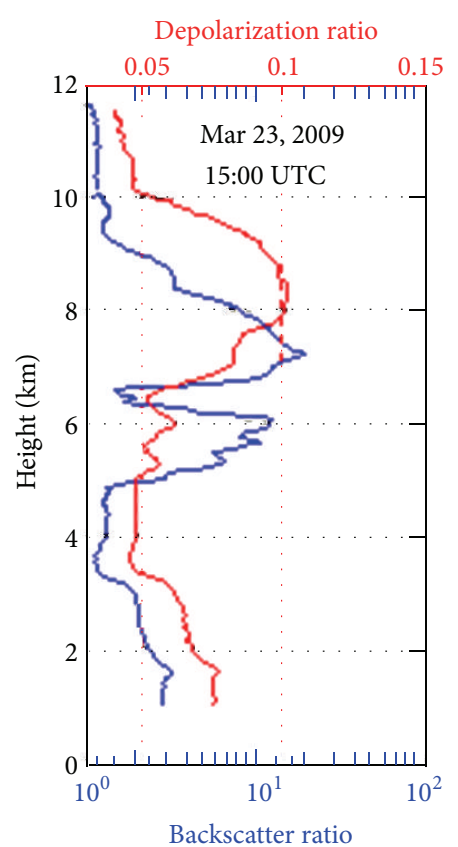

(a)

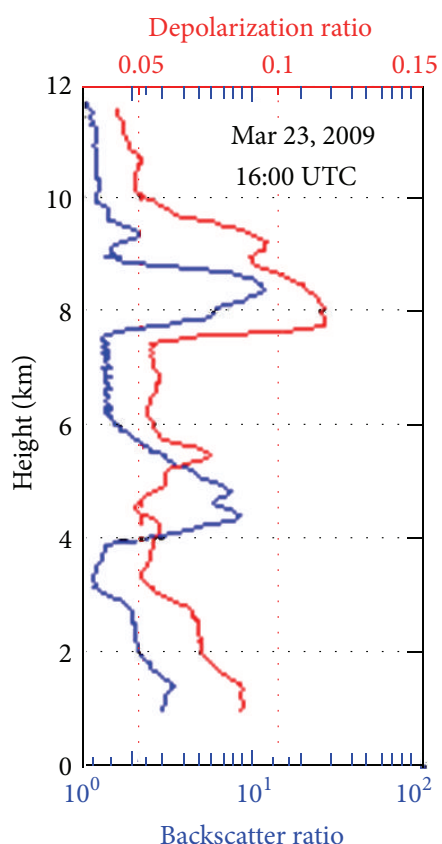

(b)

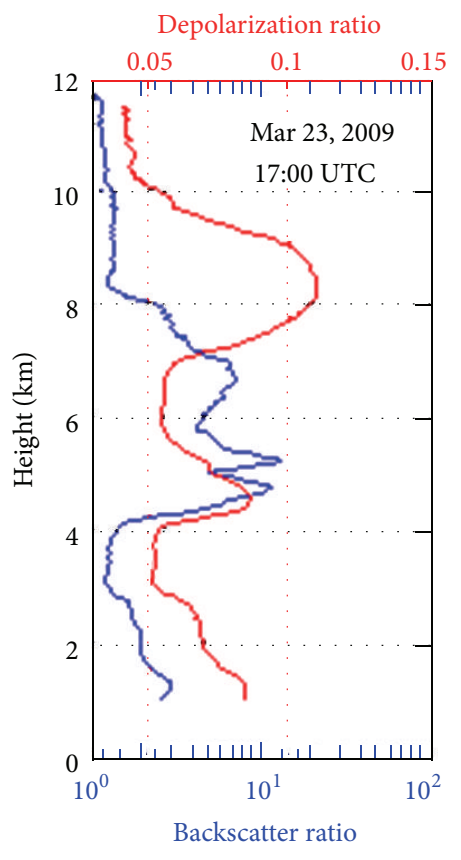

(c)

FIGURE 14: Vertical profiles of the backscatter and depolarization ratio on March 23, 2009, at 15:00, 16:00, and 17:00 UTC.

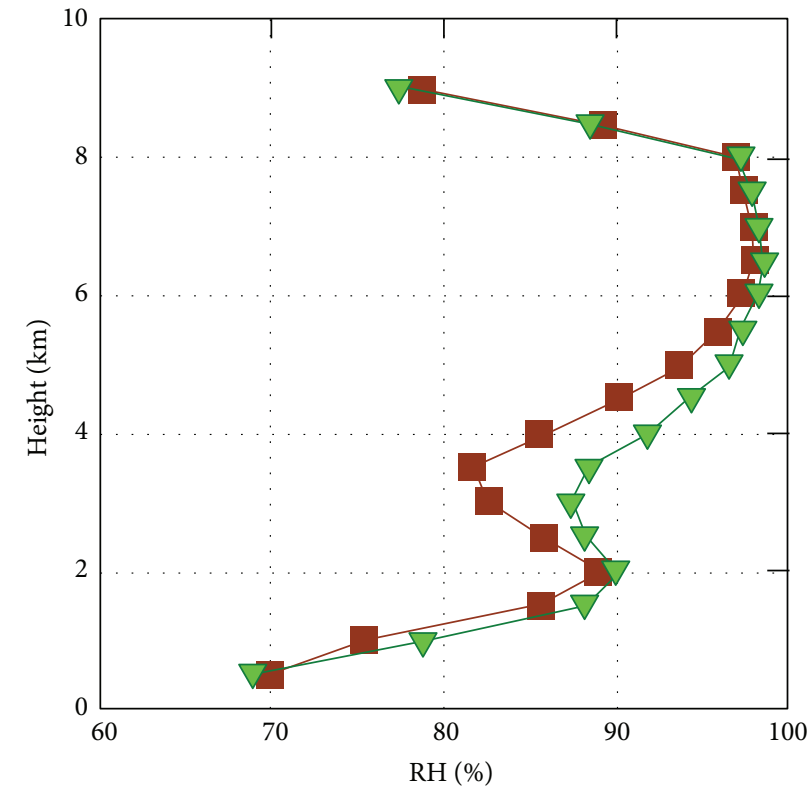

Mar 23, 2009, 15:00

Mar 23, 2009, 17:00

FIGURE 15: Vertical distribution of relative humidity on March 23, 2009, at 15:00 UTC and 17:00 UTC.

aerosol layers that were located in the free troposphere. Dust transport at this altitude was for about 4 days (96 hours).

Zonal streams of air enriched with dust in the free troposphere from the southwestern direction changed the vertical structure of the aerosol layers, resulting in large increases in its optical characteristics. The distribution of aerosol optical thickness on 22 March 2009 (NAAPS) and identification of the atmospheric aerosol type in the region based on CALIPSO measurements on 23 March 2009 are presented in Figure 17. The observed layers resulted from the mixing of anthropogenic and Arabian dust. The altitude distribution of the aerosol backscatter coefficients at 532 and $1064 \mathrm{~nm}$ and also $\mathrm{A}_{532 / 1064}$ and $\mathrm{DR}_{532}$ are shown in Figure 18. Values of the color index varying from 0.9 to 1.5 in a layer 


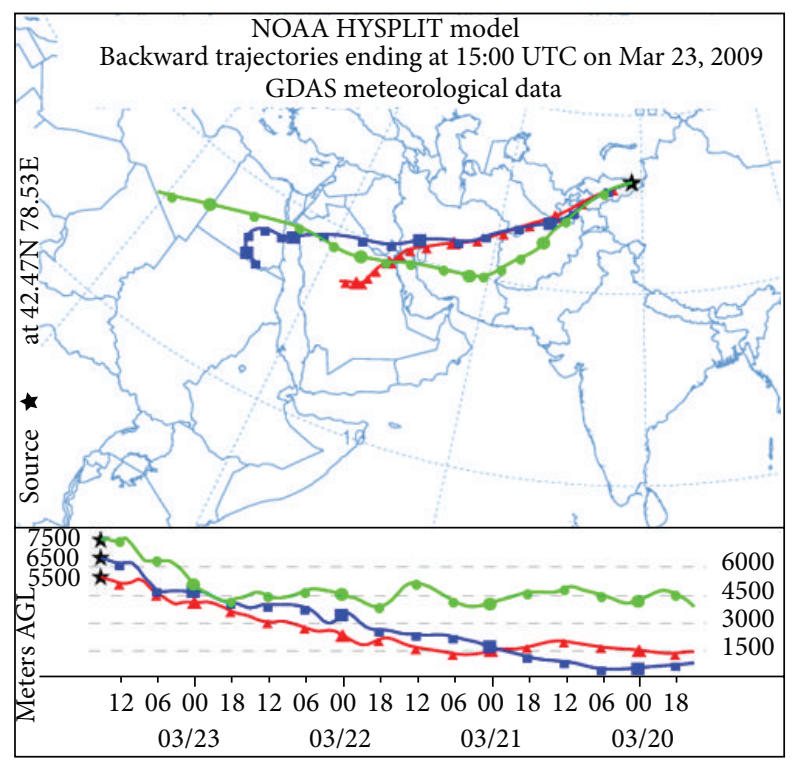

(a)

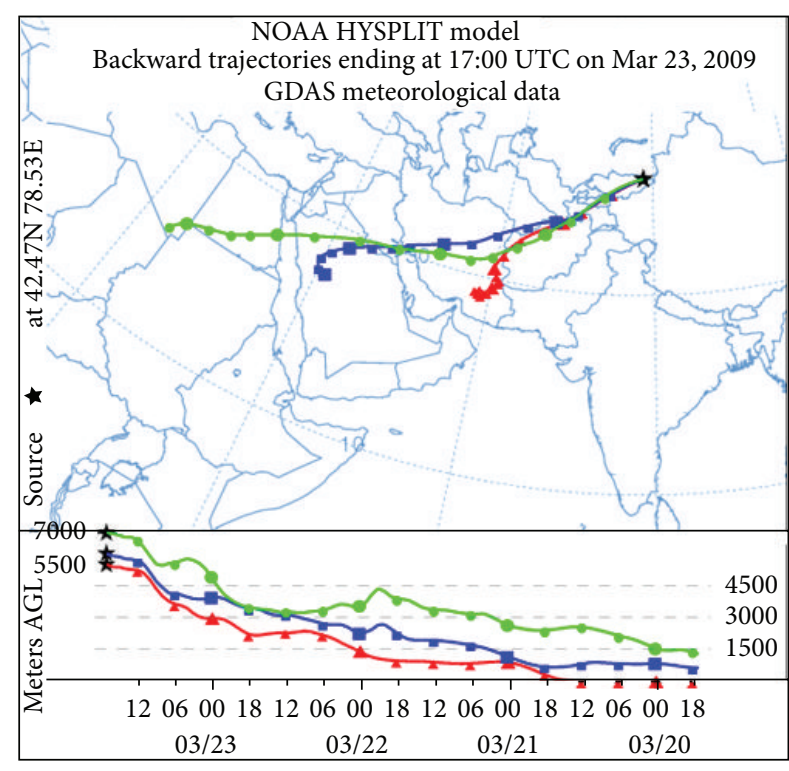

(b)

FiguRE 16: Back trajectories of air mass movement: (a) for arrival heights of 5500, 6500, and $7500 \mathrm{~m}$ (March 23, 2009, 15:00) and (b) 5500, 6000 , and $7000 \mathrm{~m}$ (March 23, 2009, 17:00).

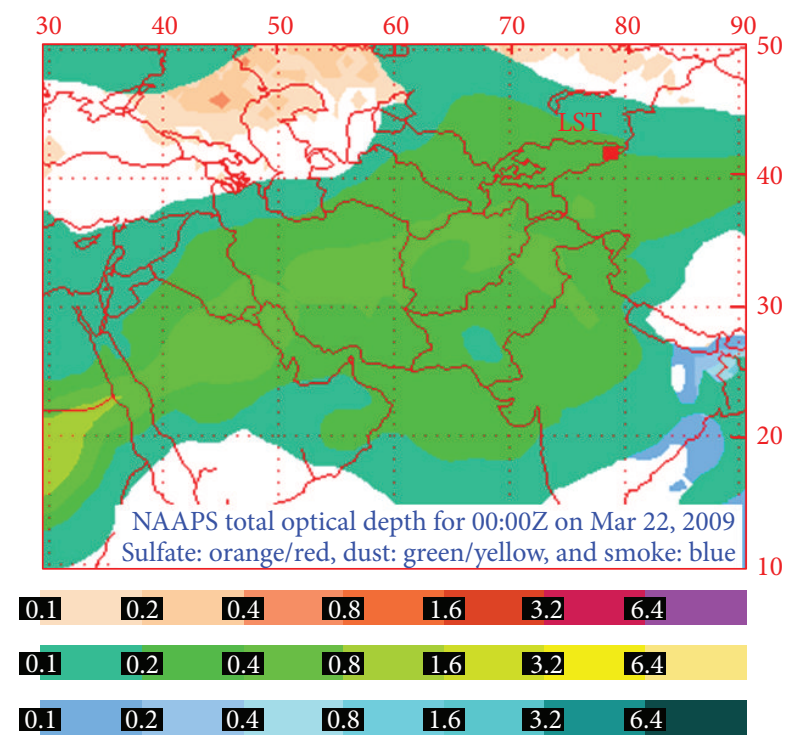

(a)

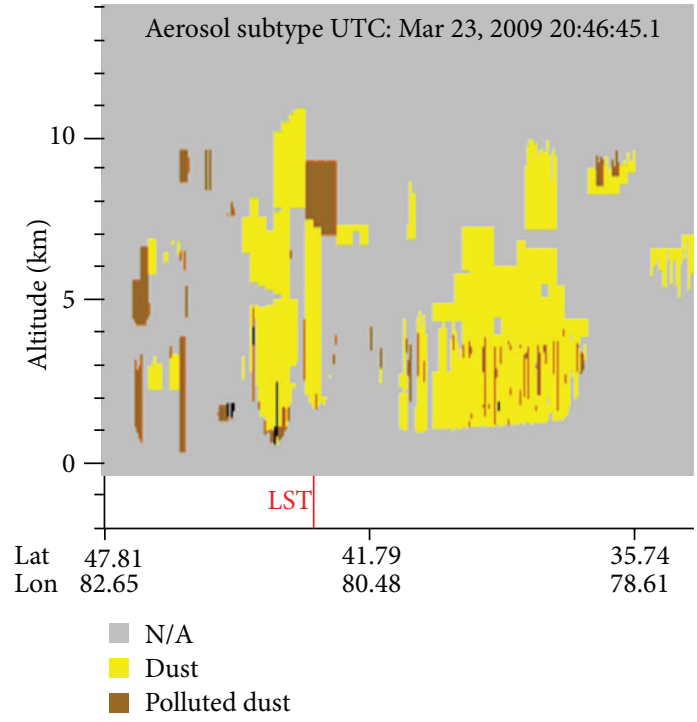

(b)

FIGURE 17: Distribution of AOD on 22 March 2009 (NAAPS) (a) and results of aerosol type identification according to CALIPSO on 23 March 2009 (b).

between 4.0 and $8.0 \mathrm{~km}$ implied the presence of two types of particles consisting of a mixture of fine anthropogenic and coarse dust. Estimation of the volumetric particle size distributions, based on Lidar measurements obtained on 23 March, 2009, at 15:00 and 17:00 UTC for heights of 5.0$9.0 \mathrm{~km}$ and $4.2-8.1 \mathrm{~km}$, respectively, is shown in Figure 19. Particle distributions were characterized by the presence of two dominating modes with a high relative contribution from fine particles. The fine mode peak had a radius equal to about $0.1-0.2 \mu \mathrm{m}$; the modal radius of the coarse fraction was $\sim 3.0 \mu \mathrm{m}$. The effective particle radius in the centre of the aerosol layer was equal to $0.35-0.75 \mu \mathrm{m}$ with the real part of the complex index of refraction, equal to $1.52-1.60$ and $0.02-$ 0.06 for imaginary part.

\section{Conclusions}

Vertical profiles of aerosol optical and physical characteristics were obtained by Lidar from June 2008 to May 2009 at a site located in Eastern Kyrgyzstan in Central Asia. Lidar measurements were supplemented with surface-based measurements of $\mathrm{PM}_{2.5}$ and $\mathrm{PM}_{10}$ mass and chemical composition of $\mathrm{PM}$ in both size fractions obtained as part of a larger study. 


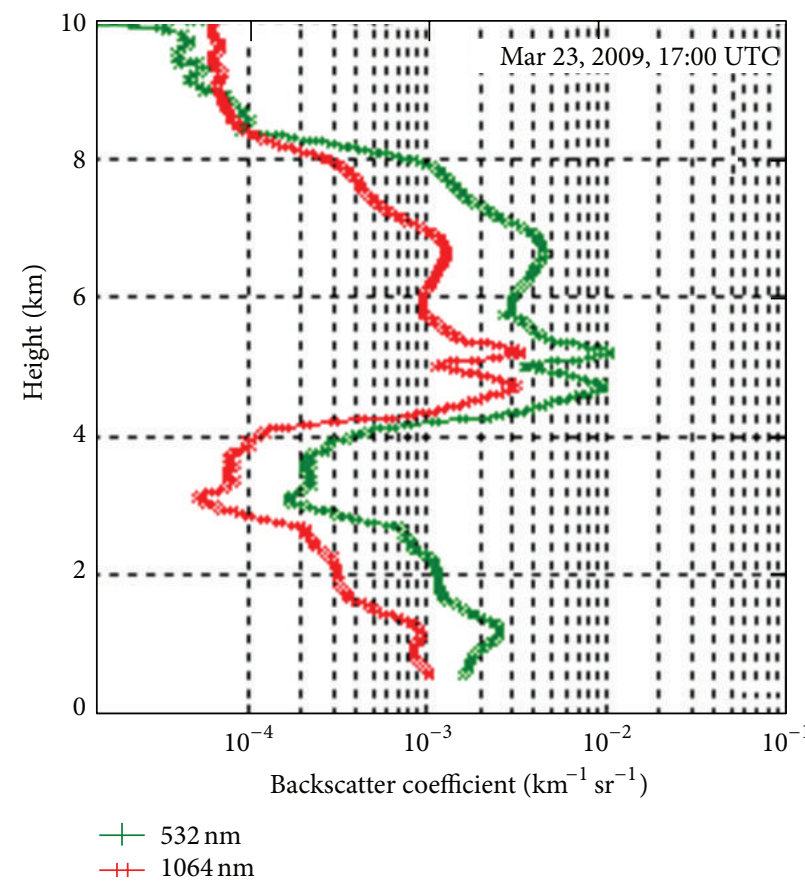

(a)

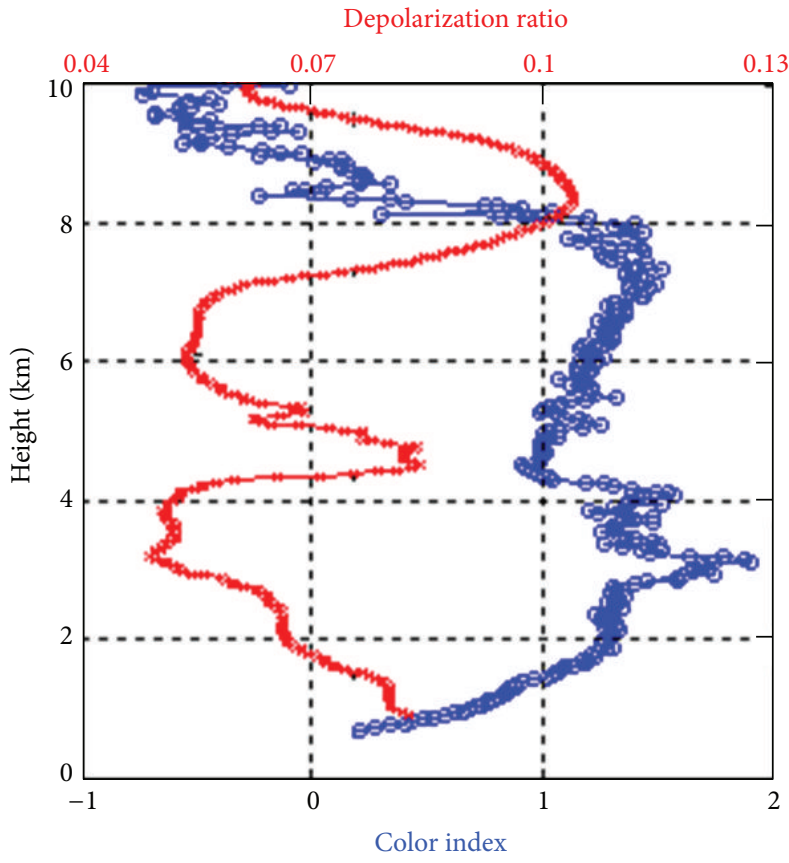

(b)

Figure 18: Profiles of aerosol backscatter coefficients at 532 and $1064 \mathrm{~nm}$ (a) and depolarization ratio and color index for backscatter coefficients at 532/1064 nm (b) on 23 March 2009.

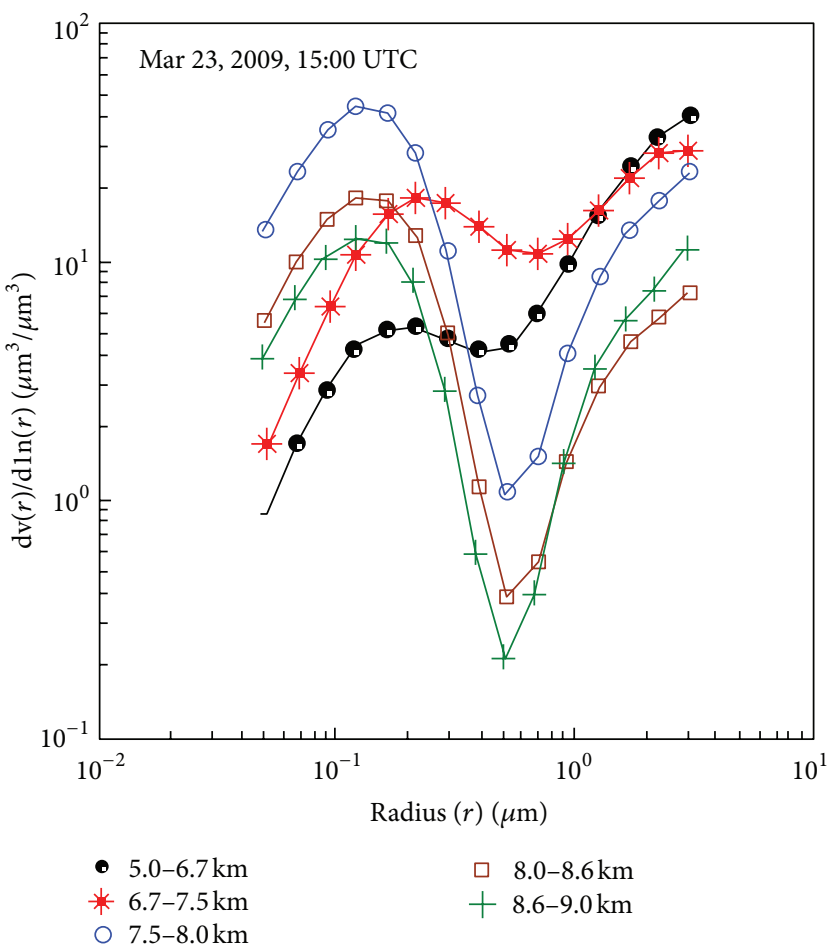

(a)

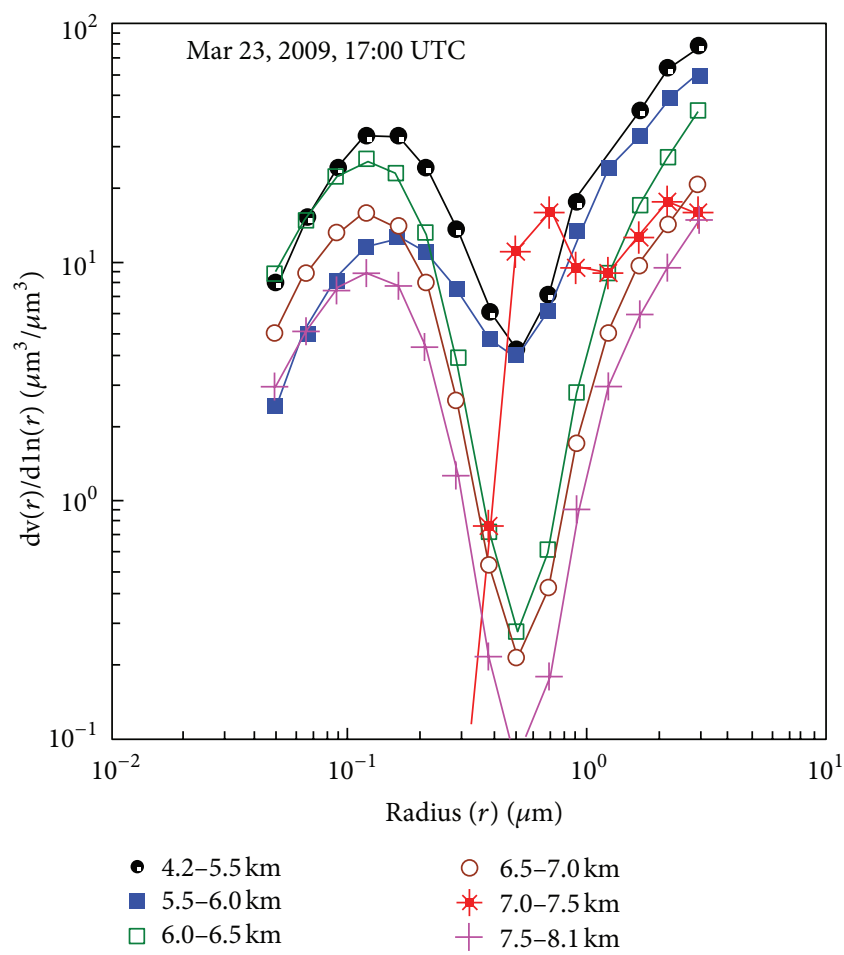

(b)

FIGURE 19: Volumetric particle size distributions, restored from Lidar measurements: (a) on 23 March 2009, 15:00 UTC and (b) on 23 March, 2009, 17:00 UTC. 
Dust particles were observed on $\sim 33 \%$ of measurement days with the maximum frequency in spring 2009. Dust transport to Central Asia came from regional sourcesTaklimakan desert and Aral Sea basin and also from longrange transport from deserts of the Middle East. Fine sulphate particles, transported from Europe, were observed on 31.5\% of days.

Seasonal variations of weather types influenced fine and coarse particle mass concentrations. Minimum or a total absence of the type CC weather condition (relatively strong vertical uplift) in conjunction with weather condition type CA (subsidence) resulted in low PM mass concentrations in autumn-winter seasons. Under these conditions, transport was from source S4 and mainly limited to within the PBL. Domination of CA (subsidence) and CI (indifferent) weather types and a slight influence of CC resulted in low particles concentrations aloft in spring season. Maximum $\mathrm{PM}_{2.5}$ and PMc concentrations were observed during summer influenced by all weather types but especially cyclonic (CC) and indifferent $(\mathrm{CI})$.

Regional sources are characterized by transport of pollution with maximum coarse particle mass concentrations, aerosol optical thickness, extinction coefficient, integral coefficient of aerosol backscatter in PBL layer, and a minimum for the fine particle mass fraction and the Ångström exponent. Transport layers stay below about $4.8 \mathrm{~km}$ in comparison with transport from other source regions.

Long-range transport (LTP) of dust from the Middle East occurs aloft at about $7.6 \mathrm{~km}$ and above. A clear distinction in aerosol characteristics was observed during the warm (spring) and cold (late autumn-winter) periods. During the cold period, dust emissions were low, resulting in low values of aerosol backscatter coefficients, coarse mass concentrations, and high values of the Ångström exponent as well as fine particle mass fraction. An increase in dust storms was observed during the transition from the cold to warm periods, which resulted in a higher fraction of coarse dust particles that affected the aerosol layer thickness and optical and microphysical characteristics of atmosphere.

Particle size distributions in the pollutant transport layers were lognormal with two modes: a dust or coarse particle mode and a fine particle mode. The particle size distribution was skewed toward smaller size particles during regional anthropogenic aerosol transport periods. The largest particles were transported from deserts located in the Middle East and Taklimakan.

The vertical distributions of aerosol optical and microphysical characteristics in pollutant transport layers from the different source regions can be used to estimate the contribution of vertical pollution layers to the aerosol radiative effect, thereby lowering uncertainty in ARF prediction with the help of models.

\section{Acknowledgments}

The US Environmental Protection Agency through its office of research and development funded this study and collaborated in the research described here under Contract
EP-D-06-001 to the University of Wisconsin-Madison as a component of the International Science \& Technology Center (ISTC) project no. 3715 (transcontinental transport of air pollution from Central Asia to the US) funded by the EPA's Office of International and Tribal Affairs and the Office of Science Policy. It has been subjected to agency review and approved for publication. Mention of trade names or commercial products does not constitute endorsement, certification, or recommendation for use.

\section{References}

[1] J. P. Miller-Schulze, M. M. Shafer, J. J. Schauer et al., "Characteristics of fine particle carbonaceous aerosol at two remote sites in Central Asia," Atmospheric Environment, vol. 45, no. 38, pp. 6955-6964, 2011.

[2] P. Forster, V. Ramaswamy, P. Artaxo et al., "Changes in atmospheric constituents and in radiative forcing," in Climate Change 2007: the Physical Science Basis. Contribution of Working Group I to the Fourth Assessment Report of the Intergovernmental Panel on Climate Change, Cambridge University Press, New York, NY, USA, 2007.

[3] J. Huang, Q. Fu, J. Su et al., "Taklimakan dust aerosol radiative heating derived from CALIPSO observations using the FuLiou radiation model with CERES constraints," Atmospheric Chemistry and Physics, vol. 9, no. 12, pp. 4011-4021, 2009.

[4] A. Papayannis, R. E. Mamouri, V. Amiridis et al., "Systematic lidar observations of Saharan dust layers over Athens, Greece in the frame of EARLINET project (2004-2006)," Annales Geophysicae, vol. 27, no. 9, pp. 3611-3620, 2009.

[5] C. Xie, T. Nishizawa, N. Sugimoto, I. Matsui, and Z. Wang, "Characteristics of aerosol optical properties in pollution and Asian dust episodes over Beijing, China," Applied Optics, vol. 47, no. 27, pp. 4945-4951, 2008.

[6] D. Müller, A. Ansmann, V. Freudenthaler et al., "Mineral dust observed with AERONET Sun photometer, Raman lidar, and in situ instruments during SAMUM 2006: shape-dependent particle properties," Journal of Geophysical Research D, vol. 115, no. 11, Article ID D11207, 2010.

[7] M. Tesche, A. Ansmann, D. Müller et al., "Vertical profiling of Saharan dust with Raman lidars and airborne HSRL in southern Morocco during SAMUM," Tellus, Series B, vol. 61, no. 1, pp. 144-164, 2009.

[8] A. Ansmann, M. Riebesell, U. Wandinger et al., "Combined raman elastic-backscatter LIDAR for vertical profiling of moisture, aerosol extinction, backscatter, and LIDAR ratio," Applied Physics B Photophysics and Laser Chemistry, vol. 55, no. 1, pp. $18-28,1992$.

[9] S. A. Imashev, P. V. Kozlov, L. G. Sverdlik, and B. B. Chen, "Methods of Lidar elastic backscatter signal processing," Journal Vestnik Kyrgyz-Russian Slavic University, vol. 11, no. 7, pp. 157164, 2011.

[10] V. A. Korshunov, "Retrieval of integral parameters of tropospheric aerosol from two-wavelength lidar sounding," Izvestiya-Atmospheric and Ocean Physics, vol. 43, no. 5, pp. 618-633, 2007.

[11] B. B. Chen, L. G. Sverdlik, and P. V. Kozlov, Optics and Microphysics of Atmospheric Aerosol, Bishkek, Kyrgyzstan, 2004.

[12] C. Ichoku, R. Levy, Y. J. Kaufman et al., "Analysis of the performance characteristics of the five-channel Microtops II Sun photometer for measuring aerosol optical thickness and 
precipitable water vapor," Journal of Geophysical Research D, vol. 107, no. D13, pp. 1-17, 2002.

[13] R. R. Draxler and G. D. Rolph, "HYSPLIT (HYbrid SingleParticle Lagrangian Integrated Trajectory) Model," 2003, http:// www.arl.noaa.gov/ready.

[14] V. P. Kurbatkin, E. S. Skiba, and V. F. Ushintseva, "Characteristic of Kyrgyzstan synoptic processes," Central Asia Institute of Hydrometeorology Research, vol. 75, no. 156, pp. 61-73, 1980.

[15] M. Lugauer, U. Baltensperger, M. Furger et al., "Aerosol transport to the high Alpine sites Jungfraujoch ( $3454 \mathrm{~m}$ asl) and Colle Gnifetti (4452 m asl)," Tellus, Series B, vol. 50, no. 1, pp. 76-92, 1998.

[16] M. Schüepp and H. Schirmer, "Climates of Central Europe," in Climates of Central and Southern Europe, vol. 6, pp. 3-73, World Survey of Climatology, 1977.

[17] B. B. Chen and L. G. Sverdlik, Optical Characteristics of the Central Tien-Shan Aerosols on the Laser Sensing Data, Bishkek, Kyrgyzstan, 2006.

[18] A. Papayannis, H. Q. Zhang, V. Amiridis et al., "Extraordinary dust event over Beijing, China, during April 2006: lidar, Sun photometric, satellite observations and model validation," Geophysical Research Letters, vol. 34, no. 7, Article ID L07806, 2007.

[19] O. Dubovik, B. Holben, T. F. Eck et al., "Variability of absorption and optical properties of key aerosol types observed in worldwide locations," Journal of the Atmospheric Sciences, vol. 59, no. 3, pp. 590-608, 2002.

[20] A. Lampert, C. Ritter, A. Hoffmann et al., "Lidar characterization of the Arctic atmosphere during ASTAR 2007: four cases studies of boundary layer, mixed-phase and multi-layer clouds," Atmospheric Chemistry and Physics, vol. 10, no. 6, pp. 28472866, 2010.

[21] A. Ansmann, I. Mattis, D. Müller et al., "Ice formation in Saharan dust over central Europe observed with temperature/ humidity/aerosol Raman lidar," Journal of Geophysical Research $D$, vol. 110, no. 18, article 27, Article ID D18S12, 2005.

[22] T. Sakai, T. Nagai, T. Kobayashi, A. Yamazaki, A. Uchiyama, and Y. Mano, "Multiwavelength and polarization lidar measurements of Asian dust layers over Tsukuba, Japan: a case study," Atmospheric Chemistry and Physics Discussions, vol. 7, no. 4, pp. 10179-10203, 2007.

[23] I. Uno, K. Eguchi, K. Yumimoto et al., "Asian dust transported one full circuit around the globe," Nature Geoscience, vol. 2, no. 8, pp. 557-560, 2009.

[24] E. Giannakaki, D. S. Balis, V. Amiridis, and S. Kazadzis, “Optical and geometrical characteristics of cirrus clouds over a Southern European lidar station," Atmospheric Chemistry and Physics, vol. 7, no. 21, pp. 5519-5530, 2007.

[25] G. Pappalardo, A. Amodeo, S. Amoruso, L. Mona, M. Pandolfi, and V. Cuomo, "One year of tropospheric lidar measurements of aerosol extinction and backscatter," Annali di Geofisica, vol. 46, no. 2, pp. 401-414, 2003.

[26] T. F. Eck, B. N. Holben, O. Dubovik et al., "Columnar aerosol optical properties at AERONET sites in central eastern Asia and aerosol transport to the tropical mid-Pacific," Journal of Geophysical Research D, vol. 110, no. D6, article 27, 2005.

[27] W.-N. Chen, F.-J. Tsai, C. C.-K. Chou, S.-Y. Chang, Y.-W. Chen, and J.-P. Chen, "Optical properties of Asian dusts in the free atmosphere measured by Raman lidar at Taipei, Taiwan," Atmospheric Environment, vol. 41, no. 36, pp. 7698-7714, 2007. 

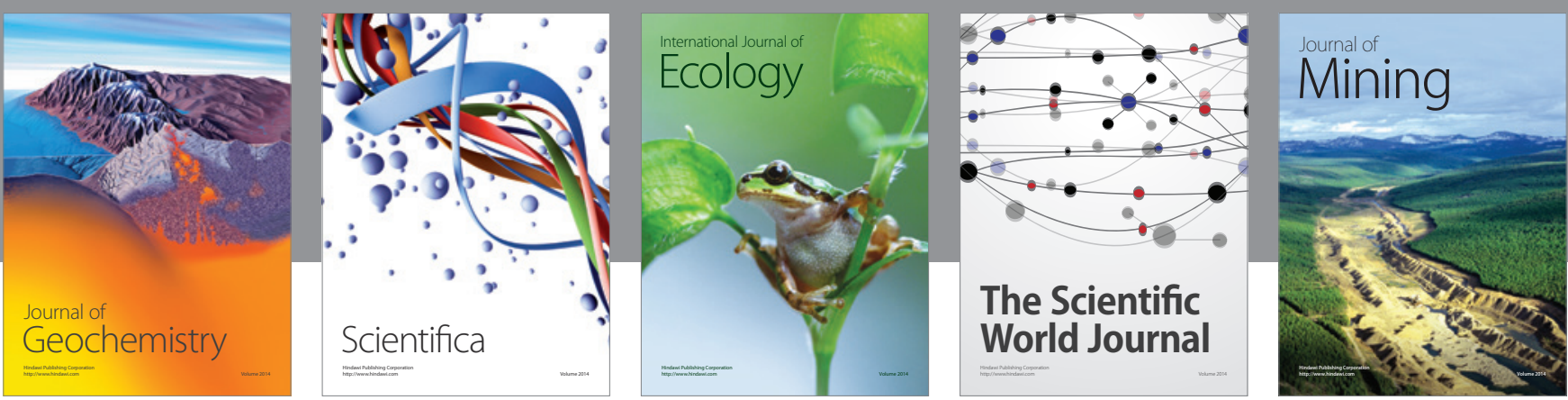

The Scientific World Journal
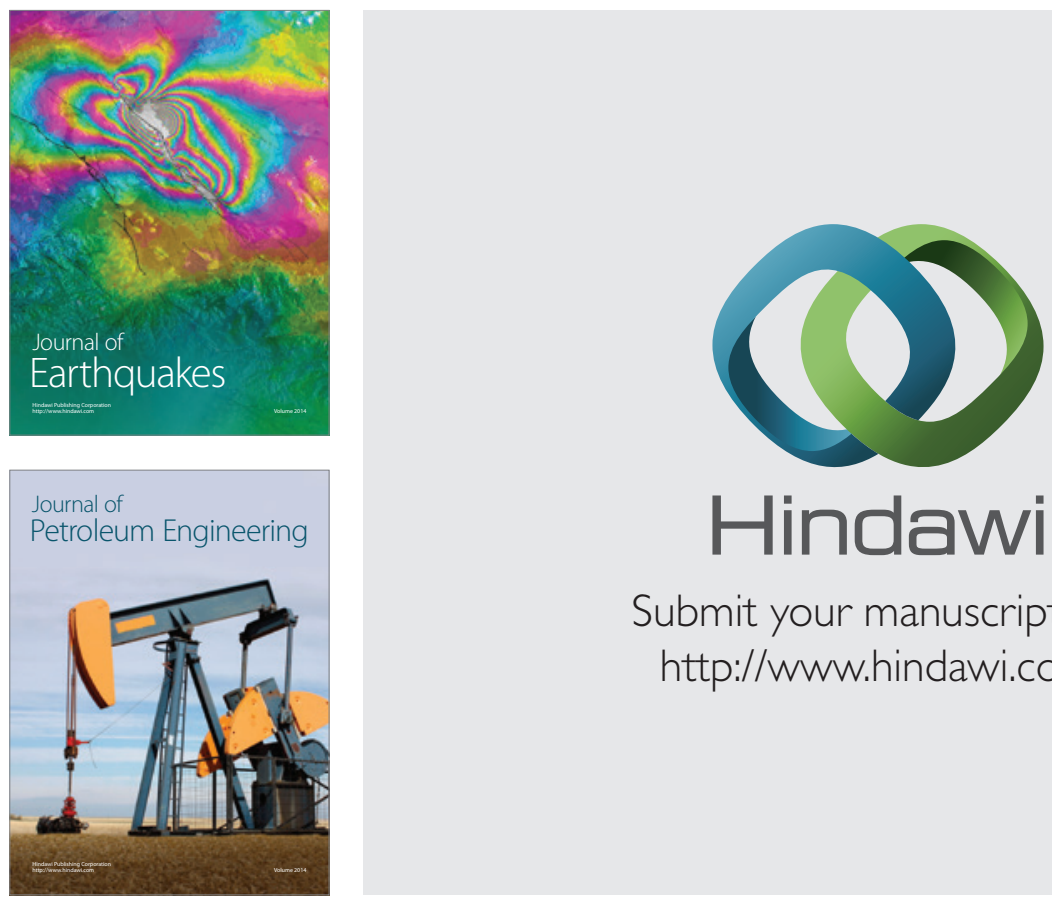

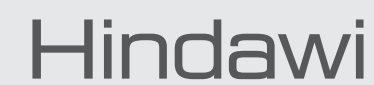

Submit your manuscripts at

http://www.hindawi.com
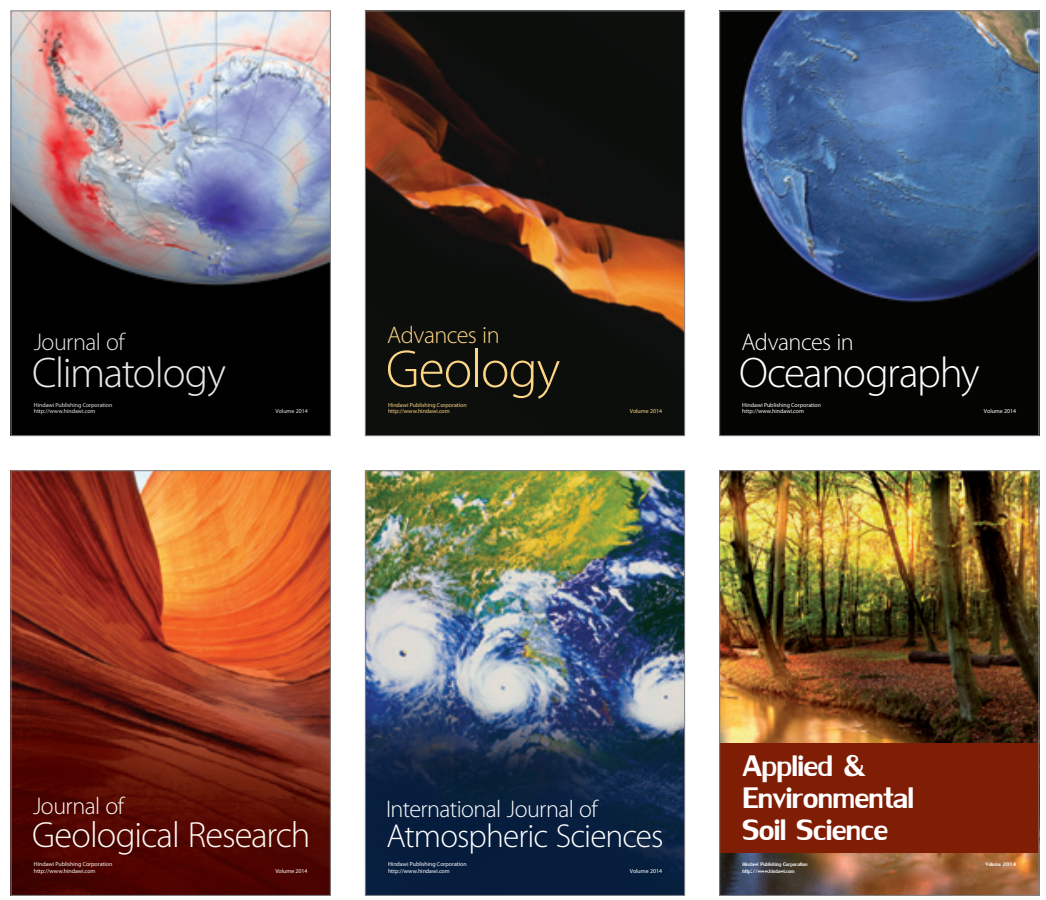
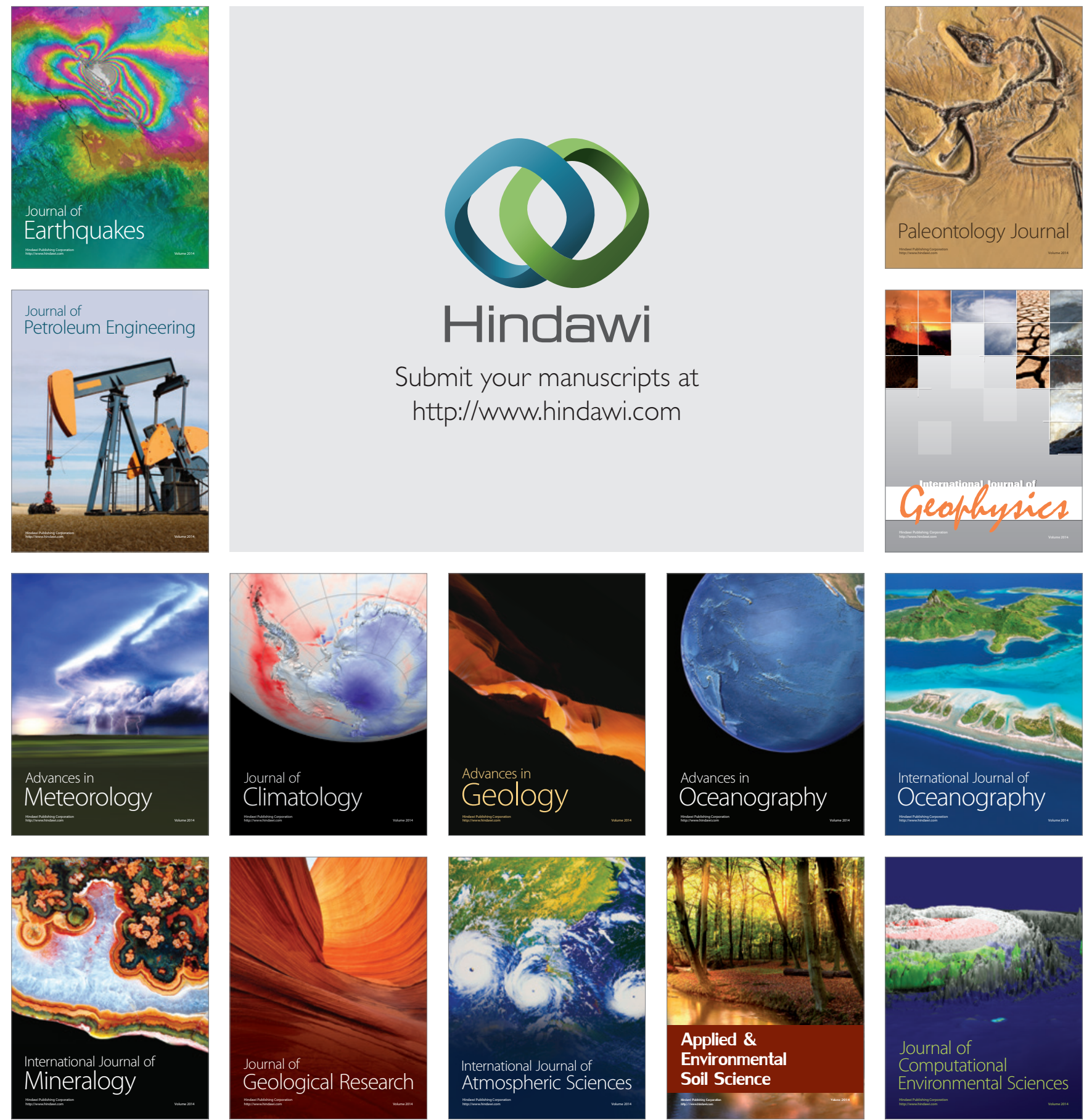